\title{
Behavior of fission gases in nuclear fuel: XAS characterization of $\mathrm{Kr}$ in $\mathrm{UO}_{2}$
}

\author{
P.M. Martin ${ }^{\text {a, }}{ }^{*}$, E. Vathonne a , G. Carlot ${ }^{a}$, R. Delorme ${ }^{a}$, C. Sabathier ${ }^{a}$, M. Freyss ${ }^{\text {a }}$, \\ P. Garcia ${ }^{\text {a }}$, M. Bertolus ${ }^{\text {a }}$, P. Glatzel ${ }^{\text {b }}$, O. Proux ${ }^{\text {c }}$ \\ ${ }^{a}$ CEA, DEN, Cadarache DEC/SESC, F-13108 St-Paul-Lez-Durance Cedex, France \\ ${ }^{\mathrm{b}}$ European Synchrotron Radiation Facility, 6 Rue Jules Horowitz, 38043 Grenoble, France \\ c OSUG, Observatoire des Sciences de l'Univers de Grenoble, CNRS and Université Joseph Fourier, BP 53, 38041 Grenoble Cedex 9, France
}

\section{A R T I C L E I N F O}

\section{Article history:}

Received 18 February 2015

Received in revised form

4 August 2015

Accepted 7 August 2015

Available online 8 August 2015

\section{Keywords:}

Nuclear fuel

XAS

Fission gases

Krypton

Uranium dioxide

Defects

\begin{abstract}
A B S T R A C T
X-ray Absorption Spectroscopy (XAS) was used to study the behavior of krypton as a function of its concentration in $\mathrm{UO}_{2}$ samples implanted with $\mathrm{Kr}$ ions. For a 0.5 at.\% krypton local concentration, by combining XAS results and DFT $+U$ calculations, we show that without any thermal treatment $\mathrm{Kr}$ atoms are mainly incorporated in the $\mathrm{UO}_{2}$ lattice as single atoms inside a neutral bound Schottky defect with $\mathrm{O}$ vacancies aligned along the (100) direction (BSD1). A thermal treatment at $1273 \mathrm{~K}$ induces the precipitation of dense $\mathrm{Kr}$ nano-aggregates, most probably solid at room temperature. In addition, $26 \pm 2 \%$ of the $\mathrm{Kr}$ atoms remain inside BSD1 showing that Kr-BSD1 complex is stable up to this temperature. Consequently, the (in-)solubility of krypton in $\mathrm{UO}_{2}$ has to be re-evaluated. For high $\mathrm{Kr}$ concentration (8 at.\%), XAS signals show that $\mathrm{Kr}$ atoms have precipitated in nanometer-sized aggregates with internal densities ranging between $4.15(7) \mathrm{g} \mathrm{cm}^{-3}$ and $3.98(5) \mathrm{g} \mathrm{cm}^{-3}$ even after annealing at $873 \mathrm{~K}$. By neglecting the effect due to the $\mathrm{UO}_{2}$ matrix, the corresponding krypton pressures at $300 \mathrm{~K}$ were equal to 2.6(3) GPa and 2.0(2) GPa, respectively. After annealing at $1673 \mathrm{~K}$, regardless of the initial $\mathrm{Kr}$ concentration, a bi-modal distribution is observed with solid nano-aggregates even at room temperature and larger cavities only partially filled with $\mathrm{Kr}$. These results are very close to those observed in $\mathrm{UO}_{2}$ fuel irradiated in reactor. In this study we show that a rare gas can be used as a probe to investigate the defect creation and their stability in $\mathrm{UO}_{2}$.
\end{abstract}

(C) 2015 Published by Elsevier B.V.

\section{Introduction}

Whether under irradiation in Pressurized Water Reactors (PWRs) or during long term storage, the microstructural evolution of oxide nuclear fuels relies notably on the creation and behavior of rare gases (RG: Xe, Kr, He). Among the chemical elements created by fission, xenon and krypton represent $\sim 30 \%$ of the created elements. Due to their very low solubility in uranium dioxide, these elements tend either to be released from the fuel or to combine with lattice defects created by fission to form nanometer size clusters [1,2]. Upon irradiation duration increases these fission gases bubbles can grow up to a few $\mu \mathrm{m}$ [3]. The core operating conditions are currently adjusted to ensure a fission gas release

\footnotetext{
* Corresponding author. CEA Cadarache, Bâtiment 717, DEN/DTEC/SECA/LCC, 13108 Saint Paul-Lez-Durance, France.

E-mail address: Philippe-m.martin@cea.fr (P.M. Martin).
}

below a critical threshold. A more accurate evaluation of fission gas release during normal or transient operation needs the assessment of the amount of RG that is trapped inside these bubbles. This could be achieved by evaluating the bubble internal pressure or gas density and the local environment of RG atoms as a function of the in-pile conditions. During long storage of spent fuel, the alpha decay of actinides leads to a continuous production of helium. This accumulation of gas which ultimately creates helium bubbles and $\alpha$-damage defects may cause fuel swelling $[4,5]$. The long term evaluation of helium behavior would require determining whether fission gas bubbles present in the fuel act as a sink for helium atoms. The trapping efficiency of bubbles would inevitably rely on their properties.

Many studies have been performed on neutron irradiated $\mathrm{UO}_{2}$ or using ion implantation with the aim of characterizing the rare gases precipitation mechanism as well as the evolution of the bubble size and distribution. A recent review details the results obtained using 
in-pile and separate effects studies [6]. Transmission Electron Microscopy (TEM) examinations performed on irradiated fuels in Light Water Reactors (LWRs) show that the bubble characteristics change slowly upon burn-up increase: bubble densities are in the $10^{23}-10^{24}$ bubbles $\mathrm{m}^{-3}$ range and their average size evolves from $\sim 1 \mathrm{~nm}$ at low burn-up to $\sim 4 \mathrm{~nm}$ for $49 \mathrm{GWd} \mathrm{t}^{-1}[7,8]$. Furthermore, Thomas et al. $[9,10]$ performed nano-EDS (Energy Dispersive X-ray Spectroscopy) on 4-10 $\mathrm{nm}$ rare gas particles (xenon + krypton) in a $44 \mathrm{GWd} \mathrm{t}^{-1}$ irradiated $\mathrm{UO}_{2}$ sample and the estimated density was in the $3.8-6.0 \mathrm{~g} \mathrm{~cm}^{-3}$ range. The higher density value would imply that these xenon + krypton nano-aggregates are solid at room temperature.

Separate effect studies performed on fresh $\mathrm{UO}_{2}$ samples implanted with $\mathrm{Kr}$ or $\mathrm{Xe}$ atoms also show the formation of nanometer-sized cavities [6,11-14]. Their density quickly saturates in the same $10^{23}-4 \cdot 10^{23}$ bubbles $\mathrm{m}^{-3}$ range as found in spent fuels. These values are obtained for an RG local concentration below 0.1 at.\% [11]. However, no elementary signal for rare gases was observed using nano-EDS in these studies. Therefore, it was not possible to determine if the observed cavities were filled with RG atoms or not. Furthermore, a recent study performed on $\mathrm{UO}_{2}$ thin foil samples irradiated with $4 \mathrm{MeV} \mathrm{Au}$ ions only shows the formation of nano-voids due to radiation damage [15]. The cavity density was equal to $4.5 \times 10^{23}$ cavity $\mathrm{m}^{-3}$ with a $0.9 \pm 0.4 \mathrm{~nm}$ diameter. These values are very similar to those obtained on samples implanted with RG atoms. These nanovoids are likely to act as sinks for insoluble elements in $\mathrm{UO}_{2}$ like $\mathrm{RG}$ but their efficiency remains to be evaluated.

Except in a few cases, rare gas density within nanometer size bubbles cannot be determined from TEM experiments. Such information can however be deduced from X-ray Absorption Spectroscopy (XAS) measurements. Several papers deal with the evolution of krypton K-edge XANES (X-ray Absorption Near Edge Spectra) and EXAFS (Extended X-ray Absorption Fine Structure) spectra collected on pure krypton pressurized between 0.3 and $29 \mathrm{GPa}$ in a diamond anvil cell [16,17]. Experimental equations of state linking the $\mathrm{Kr}-\mathrm{Kr}$ first neighbor distance derived from either XANES or EXAFS to the pressure were obtained at room temperature. Furthermore, the krypton behavior in Be [18], Al [19], Nb [19], $\mathrm{Si}$ [18], $\mathrm{SiO}_{2}$ glass [20], amorphous $\mathrm{C}[19,21]$ or fullerene $\mathrm{C}_{60}[22]$ was studied using XAS. In metallic $\mathrm{Be}, \mathrm{Al}$ and $\mathrm{Nb}$ and in Si samples implanted with $\mathrm{Kr}$ ions and subsequently annealed, XANES spectra collected at low temperature $(4 \mathrm{~K}$ or $77 \mathrm{~K}$ ) allowed the authors to demonstrate the precipitation of $\mathrm{Kr}$ bubbles and to estimate the Kr pressure within aggregates (3-10 GPa range) [18,19]. To our knowledge, only one study dealing with $\mathrm{Kr}$-implanted $\mathrm{UO}_{2}$ using XAS is available in the open literature. In this study, Degueldre et al. [23] determined that the krypton local environment in a $44 \mathrm{GWd} \mathrm{t}^{-1}$ irradiated $\mathrm{UO}_{2}$ fuel was mainly governed by the presence of xenon atoms inside (xenon-krypton) particles/ aggregates. The rare gas density inside these particles was evalu-

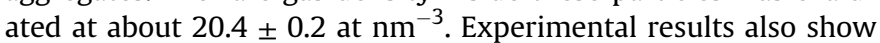
that $\mathrm{Kr}$ atoms are bound only to matrix atoms as in Wulf et al. [20] and Ito et al. [22] studies on $\mathrm{SiO}_{2}$ and $\mathrm{C}_{60}$ respectively. However, the identification of the defects associated with $\mathrm{Kr}$ atoms needs a comparison with the structure derived from Density Functional Theory (DFT) calculations. The incorporation of $\mathrm{Kr}$ atoms in $\mathrm{UO}_{2}$ has been the subject of previous computational studies [24-27]. For the three first studies cited, regardless of the method used (classical potential [24], DFT [25,26] and DFT $+U$ [26]) the most stable location for $\mathrm{Kr}$ atom is a pre-existing neutral Schottky defect (2 oxygen +1 uranium vacancies). In Tian et al. work using SpinPolarized DFT calculations (SP-GGA $+U$ method) [27], authors concluded that the most stable site for the $\mathrm{Kr}$ atoms was a divacancy ( 1 oxygen +1 uranium vacancies). After optimization, the atomic positions obtained with DFT calculations can be used as input data in codes like FDMNES [28] to simulate XANES spectra.

The present work focuses on the behavior of krypton in fresh $\mathrm{UO}_{2}$ samples using XAS (EXAFS and XANES). The experimental results were obtained on $\mathrm{Kr}$-implanted $\mathrm{UO}_{2}$ with various beam conditions in order to study the influence of both local concentration (0.5-8.0 at.\%) and penetration depth (120-1200 nm) of this RG. The samples were then annealed between $873 \mathrm{~K}$ and $1673 \mathrm{~K}$ under a dry reducing atmosphere $\left(\mathrm{Ar}-5 \% \mathrm{H}_{2}\right)$. As detailed in the Experimental and computational Section, XAS data were collected at the European Synchrotron Radiation Facility (Grenoble, France). The details about DFT calculations performed with the VASP code and XANES simulation using the FDMNES code are also given. The results section is organized as follows. First, we give results on $\mathrm{Kr}$ implanted samples mirroring previous studies on Xe-implanted ones, i.e. with 8.0 at.\% of RG located at $120 \mathrm{~nm}$ from sample surface [29]. Second subsection, based on the spectra obtained on 0.5 at.\% Kr-doped samples, the local environment of isolated krypton atoms in the $\mathrm{UO}_{2}$ matrix is detailed. The results of the DFT $+U$ calculations of $\mathrm{Kr}$ incorporation in various point defects in the $\mathrm{UO}_{2}$ fluorite structure are presented and used as input data for the XANES simulations and compared with the experimental ones. The results on the thermal stability of isolated $\mathrm{Kr}$ atoms in the 1473-1673 K range are detailed in third subsection. In the next step (discussion part), values of $\mathrm{Kr}$ density within nano-aggregates and associated internal pressure are calculated and compared to the results available on both $\mathrm{UO}_{2}$ implanted with xenon and irradiated $\mathrm{UO}_{2}$ fuel samples. The stability of the $\mathrm{Kr}$-defect complex is then discussed. Finally, our conclusions are presented in the last section.

\section{Experimental and computational methods}

\subsection{Sample preparation}

Polycrystalline depleted uranium $\left(0.3 \%{ }^{235} \mathrm{U}\right) \mathrm{UO}_{2}$ pellets with a density equal to $98 \%$ of the theoretical value $\left(\rho=10.75 \mathrm{~g} \mathrm{~cm}^{-3}\right)$ were cut into disks of about $500 \mu \mathrm{m}$ thickness. Typical grain size is about $10 \mu \mathrm{m}$. Discs were polished (diamond finish) and then annealed $4 \mathrm{~h}$ under a dry reducing atmosphere $\left(\mathrm{Ar}-5 \% \mathrm{H}_{2}\right)$ atmosphere at $1673 \mathrm{~K}$ in order to remove damage induced by polishing and to guarantee an oxygen stoichiometry close to oxygen/ uranium $=2.00$.

Samples were implanted with $\mathrm{Kr}$ ions using one of the three conditions ( $\mathrm{A}, \mathrm{B}$, or $\mathrm{C}$ ) detailed in Table 1 . The implantations using a $400 \mathrm{keV} \mathrm{Kr}^{+}$beam (A) were performed at the Institut de Physique Nucléaire de Lyon (IPNL, Villeurbanne, France). The implantations with conditions B and C were carried out at the INstitut d'Electronique du Solide et des Systèmes (INESS, Strasbourg, France) using a $1 \mathrm{MeV}$ or a $4 \mathrm{MeV} \mathrm{Kr}^{+}$beam. The atomic distribution of krypton atoms in $\mathrm{UO}_{2}$ were evaluated using the SRIM code [30] with threshold displacement energy values of 40 and $20 \mathrm{eV}$ for uranium and oxygen, respectively. The resulting implantation profiles and associated distributions of displacements per atom (dpa) are compared in Fig. 1.

After implantation, samples were annealed at the Laboratoire Bernard François (LBF) at CEA Cadarache (France) under dry $\mathrm{Ar}-\mathrm{H}_{2}$ (5\%) gas mixture at temperatures ranging from $873 \mathrm{~K}$ to $1673 \mathrm{~K}$.

\subsection{X-ray absorption spectroscopy}

\subsubsection{Data collection}

Kr K-edge (14,260 eV) XAS data were measured at the European Synchrotron Radiation Facility (ESRF) (Grenoble, France). The samples implanted with conditions A were analyzed at the French Absorption beamline in Material and Environmental Science 
Table 1

Implantation conditions, atomic concentrations and range of $\mathrm{Kr}$ atoms calculated using SRIM code [30].

\begin{tabular}{|c|c|c|c|c|c|}
\hline & \multicolumn{2}{|c|}{ Implantation conditions } & \multicolumn{2}{|l|}{ Kr distribution } & \multirow[t]{2}{*}{ Displacement per atoms (dpa) } \\
\hline & Energy $(\mathrm{KeV})$ & Fluence $\left(10^{16}\right.$ at $\left.\mathrm{cm}^{-2}\right)$ & Maximum concentration (at. \%) & Depth (nm) & \\
\hline A & 400 & 10 & 8 & 120 & 420 \\
\hline B & 1000 & 1.2 & 0.5 & 300 & 47 \\
\hline $\mathrm{C}$ & 4000 & 3 & 0.5 & 1200 & 84 \\
\hline
\end{tabular}

(a)

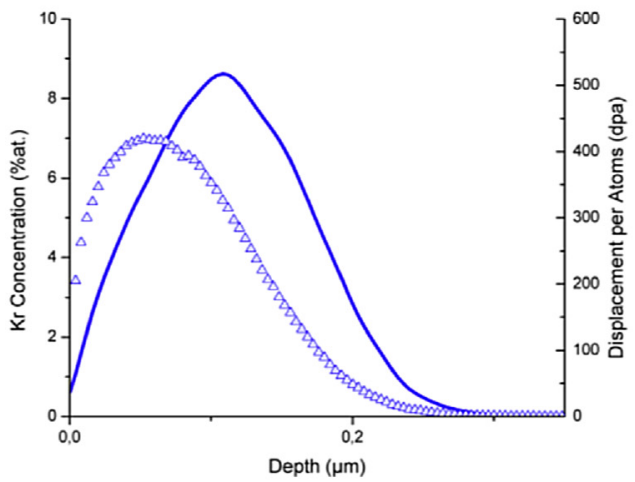

(b)

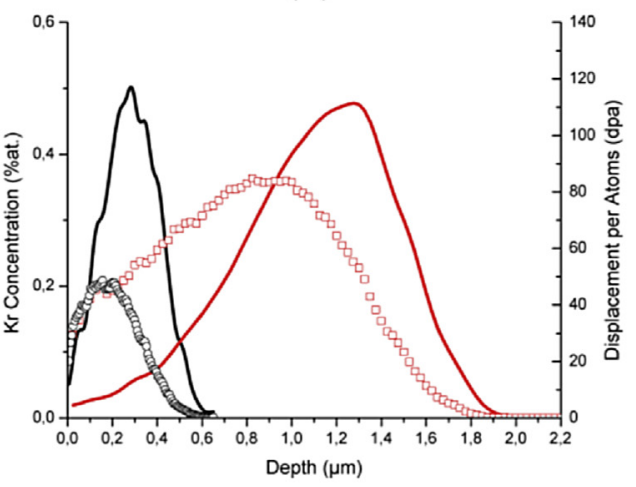

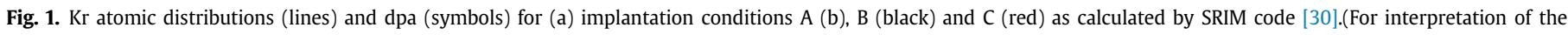
references to color in this figure legend, the reader is referred to the web version of this article.)

beamline (FAME, BM30B). FAME is a bending magnet beamline equipped with a liquid nitrogen-cooled double crystal $\mathrm{Si}(220)$ monochromator surrounded by two Rh-covered mirrors. The energy resolution is close to the intrinsic resolution of the monochromator $(0.74 \mathrm{eV}$ at the $\mathrm{Kr}$ K-edge [31,32]). The beam was focused to $300 \times 200 \mu \mathrm{m}^{2}\left(\mathrm{H} \times \mathrm{V}\right.$, FWHM). The incident $\left(\mathrm{I}_{0}\right)$ and transmitted $\left(\mathrm{I}_{1}\right)$ intensities were measured by $\mathrm{Si}$ photodiodes collecting the Xrays scattered by air. The fluorescence photons were measured using a 30-element Ge solid-state detector. Fluorescence count numbers were maximized by setting the angle between the incoming X-ray beam and sample surface to $10^{\circ}$. A Kr XAS spectrum was collected at room temperature in transmission mode using a dedicated cell filled with $\mathrm{Kr}$ gas. Energy calibration was performed by setting the first inflexion position of XANES spectrum to the tabulated value of $14326 \mathrm{eV}$ [33].

Kr K-edge XANES and EXAFS spectra for samples implanted with conditions B and C were collected at beamline ID26 [34]. For the selection of the necessary excitation energy a double $\mathrm{Si}(111)$ monochromator was used. Two curved mirrors were used for focusing. High resolution XANES spectra were obtained using a Crystal Analyzer Spectrometer (CAS) and a Silicon Drift Detector (SDD) as X-rays detector [35]. The sample, analyzing crystals and SDD were arranged in a vertical Rowland geometry. Four spherically curved $\mathrm{Ge}(220)$ crystals were used as analyzing crystals. Krypton K-edge High Energy Resolution Fluorescence Detection (HERFD)-XAS spectra were measured by registering the $\mathrm{K}_{\alpha 1}\left(\mathrm{~K}-\mathrm{L}_{3}\right.$ transition) fluorescence peak intensity (12647 eV). The gain in Xray detection energy bandwidth obtained with CAS (a few eV compared to the $\sim 250 \mathrm{eV}$ for SDD) permitted to remove the spurious signals due to the Bragg peaks from the $\mathrm{UO}_{2}$ matrix. This phenomenon usually prevents the collection of XAS spectra using a fluorescence line as the probed element is diluted (<1 at.\%) [36]. The total fluorescence spectra were simultaneously collected using another SDD. The angle between the sample surface and the incoming X-ray beam was set to $45^{\circ}$. Data collected on ID26 were calibrated (in energy) after the experiment by determining the energy shift between the HERFD-XANES spectra collected at room temperature on the same sample (conditions A annealed for $12 \mathrm{~h}$ at $873 \mathrm{~K}$ ) on FAME.

On both beamlines, XANES spectra were collected at $15 \mathrm{~K}$ using a liquid He cryostat and at room temperature. The EXAFS data were recorded at $15 \mathrm{~K}$.

\subsubsection{XANES/EXAFS data extraction}

The ATHENA software [37] was used to normalize XANES spectra oscillations from the raw absorption data. Linear functions were used for both pre-edge removal and normalization. The postedge line for XANES spectra was taken using the position $+40 \mathrm{eV}$ and $+90 \mathrm{eV}$ relatively to $\mathrm{E}_{0}$ position. The $\mathrm{E}_{0}$ values were taken at the first inflection point using the first maximum of the first derivative. The position of the white line maximum was selected with the first zero-crossing of the first derivative.

As described by Di Cicco et al. [17] the particularity of Kr K-edge XAS spectra is the existence of several double-excitations in the atomic background. To extract reliable local description these double-excitation must be removed. Two solutions were tested: the method described by Di Cicco et al. [17] to build an atomic background function using simple empirical functions reproducing the shape of the double-excitation channels by using of a spectrum collected on gaseous $\mathrm{Kr}$ atomic background [38]. The second was preferred as it allowed a better removal of the low-frequency peak in the $0-1$ A region of the Fourier Transform of $\chi(\mathrm{k})$.

The EXAFS analyses were performed using the ARTEMIS [37] with FEFF code version 8.40 [39]. During fitting, k-space data were weighted by $\mathrm{k}^{\mathrm{n}}(\mathrm{n}=1,2,3)$. A Hanning window was used to select the k-space data range from 3.3 to $8.5 \AA^{-1}$ depending on data quality, and fitting was performed in R-space over a 1.5 to $4.4 \AA$ range.

The XANES spectra were calculated using the FDMNES package [28]. The final states and resulting absorption cross sections were calculated using the muffin-tin approximation. Relativistic effects were taken into account (relativism keyword). The self-consistent 
calculation of the Fermi level was performed using the SCF keyword. In the case of HERFD-XANES, a $1.10 \mathrm{eV}$ value was used to reproduce the broadening due to the core-hole lifetime [40]. This value was obtained using the core-hole lifetime values corresponding to krypton $\mathrm{L}_{3}(1.17 \mathrm{eV})[41]$ and $\mathrm{K}(2.75 \mathrm{eV})$ [41] edges, respectively.

The atomic coordinates used to build the input file for FEFF or FDMNES calculations were determined using the Fm-3m crystallographic structure of solid krypton or the atomic positions obtained from DFT $+U$ calculations. In the latter case, the FDMNES simulations were done using a cluster radius of $5 \AA$ around the central $\mathrm{Kr}$ atom.

\subsection{3. $D F T+U$ calculations}

The calculations were performed using the projector augmented wave method (PAW) $[42,43]$ as implemented in the Vienna ab initio simulation package (VASP) [44-46]. The Generalized Gradient Approximation (GGA) as parameterized by Perdew, Burke and Ernzerhof (PBE) [47] was used to describe the exchange-correlation interactions. Moreover, a Hubbard-like term was added in order to take into account the strong correlations between the $5 f$ electrons of the uranium atoms, in the Liechtenstein scheme [48] of the so-called DFT $+U$ method. The values of the $U$ and $J$ parameters were set to $4.5 \mathrm{eV}$ and $0.51 \mathrm{eV}$ respectively, in agreement with earlier DFT $+U$ calculations [49] and the values extracted from experiments [50]. In order to avoid the possible metastable states yielded by the DFT $+U$ method and find reliable structures, we used the occupation matrix control scheme to ensure that the ground state was reached [51].

Above $30.8 \mathrm{~K}$, uranium dioxide is paramagnetic and antiferromagnetic below this temperature. However, due to the difficulty to model paramagnetic systems in DFT $+U$, we considered the antiferromagnetic order in our calculations. All our calculations include spin polarization with a $\mathbf{1 k}$ antiferromagnetic ordering. This antiferromagnetic configuration is an approximation of the noncollinear 3k order seen experimentally below $30 \mathrm{~K}$ [52]. Considering this order would require too much computational time and the total energy difference between the 2 magnetic configurations is small [53]. The calculations were performed within a $2 \times 2 \times 2$ (96 atoms for stoichiometric $\mathrm{UO}_{2}$ ) supercell expansion of the fluorite unit cell. A $2 \times 2 \times 2$ Monkhorst-Pack k-point mesh [54] with a Gaussian smearing of $0.1 \mathrm{eV}$ was used for all calculations. We used a plane wave cutoff energy of $500 \mathrm{eV}$ in agreement with our cutoff convergence tests on stoichiometric $\mathrm{UO}_{2}$. The lattice parameters and atomic positions were relaxed during the calculations and symmetries of the system were taken into account. We relaxed the structures until we reached a convergence of the Hellmann-Feynman forces less than $0.005 \mathrm{eV}^{-1}$. In addition, we checked that the total energy of the system is converged to less than $0.01 \mathrm{meV}$ atom $^{-1}$. With these conditions we found the lattice parameters to be $\mathrm{a}=\mathrm{b}=5.57 \AA$ and $\mathrm{c}=5.49 \AA$ for stoichiometric $\mathrm{UO}_{2}$ compared to the $5.47 \AA$ observed experimentally [55]. The distortion in the $\mathrm{z}$ axis is due to the $\mathbf{1 k}$ antiferromagnetic order considered.

\section{Results}

\subsection{High $\mathrm{Kr}$ content (8 at.\% - conditions A)}

The results obtained on the 3 samples implanted using conditions $\mathrm{A}$ are detailed in this part. The influence of annealing on $\mathrm{Kr}$ behavior was studied on the samples thermally treated for $12 \mathrm{~h}$ at $873 \mathrm{~K}$ and for $1 \mathrm{~h}$ at $1673 \mathrm{~K}$. These temperatures correspond to the fuel periphery steady-state and transient thermal conditions during in-pile operation, respectively [1]. The XANES and EXAFS results are presented in two separate sections.

\subsubsection{XANES}

The XANES spectra collected at $15 \mathrm{~K}$ and $300 \mathrm{~K}$ are compared in Fig. 2. All spectra exhibit the same features: an intense white line followed by a second broad peak located $\sim 15-17 \mathrm{eV}$ above the threshold. In the literature, very similar spectra were observed for solid $\mathrm{Kr}$ [17] or dense $\mathrm{Kr}$ aggregates in Be and $\mathrm{Si}$ [18]. This would suggest that krypton atoms are surrounded only by other $\mathrm{Kr}$ atoms in dense nano-aggregates for the three samples. Moreover, the observation of such XANES spectra at $300 \mathrm{~K}$, shows that a local symmetry around the $\mathrm{Kr}$ atoms is observed at room temperature. This clearly indicates that the Kr density within the krypton aggregates is sufficiently high, even at room temperature, and suggests that $\mathrm{Kr}$ atoms have an organized local environment consistent with solid state $\mathrm{Kr}$ nano-aggregates.

From XANES spectra, the energy positions of both the threshold and the maximum of the second peak were extracted and are given in Table 2. For the spectra collected at $300 \mathrm{~K}$, the position of the second peak could not be determined due to the insufficient signal to noise ratio. The $\Delta \mathrm{E}$ values in Table 2 can be used to follow the evolution of $\mathrm{Kr}-\mathrm{Kr}$ distances in krypton aggregates. A shortening of $\mathrm{Kr}-\mathrm{Kr}$ bonds induces an increase in the white line intensity and a shift to a higher energy of both the second maximum and the threshold $\left(\mathrm{E}_{0}\right)$ positions. The decrease in the $\mathrm{Kr}-\mathrm{Kr}$ distances is the consequence of an increasing $\mathrm{Kr}$ density $[16,17]$.

As observed in Fig. 2a, spectra collected at $15 \mathrm{~K}$ and $300 \mathrm{~K}$ on the as-implanted sample and on the sample annealed at $873 \mathrm{~K}$ are almost identical. The $\mathrm{E}_{0}$ position remains equal to $14326.4(2) \mathrm{eV}$ and the intensity of both the white line and the second peak are not modified. Only a slight decrease in $\Delta \mathrm{E}$ from $16.5(2) \mathrm{eV}$ to $16.3(2) \mathrm{eV}$ was observed. As a consequence, this thermal treatment only leads to a slight increase in the $\mathrm{Kr}-\mathrm{Kr}$ distances, indicating a decrease in the $\mathrm{Kr}$ density inside the associated aggregates.

The spectrum collected at $15 \mathrm{~K}$ on the sample annealed for one hour at $1673 \mathrm{~K}$ indicates an important evolution: a $0.5 \mathrm{eV}$ shift of the white line toward lower energy; both the white line and the second peak intensity are more intense and $\Delta \mathrm{E}$ is equal to $14.8 \mathrm{eV}$. A significant decrease in the average $\mathrm{Kr}-\mathrm{Kr}$ distances is therefore observed. Furthermore, as illustrated in Fig. 3, unlike the previous conditions, the spectra collected at 15 and $300 \mathrm{~K}$ exhibit large differences in this case. This indicates that a modification of the physical state (solid state to gas/liquid) of the $\mathrm{Kr}$ aggregates takes place between 15 and $300 \mathrm{~K}$. Consequently after a thermal treatment at $1673 \mathrm{~K}$ for one hour, a large proportion of krypton is in a gaseous state at room temperature.

\subsubsection{EXAFS results}

The EXAFS spectra collected at $15 \mathrm{~K}$ and their associated Fourier transforms are shown in Fig. 4. One main peak centered between 3.7 and $4 \AA$ is observed in the Fourier transforms for the three samples (see Fig. 4b). As observed in the XANES spectra, the modifications induced by a thermal treatment at $873 \mathrm{~K}$ for $12 \mathrm{~h}$ are limited: a minor decrease in intensity and a slight shift of the peak located at $\sim 3.7 \AA$ to a longer distance. Interatomic distances (R), number of neighbors $(\mathrm{N})$ and Debye Waller factor $\left(\sigma^{2}\right)$ values obtained from the EXAFS fit are given in Table 3.

In the as-implanted sample, EXAFS results show that krypton atoms are surrounded by $4.8(5) \mathrm{Kr}$ atoms at 3.62(2) A. Furthermore, no coordination shell with matrix atoms (i.e. oxygen or uranium) was detected. At $15 \mathrm{~K}$, krypton is in solid state with a face centered cubic (fcc) structure and the first coordination sphere around $\mathrm{Kr}$ consists in 12 krypton atoms at $4.00 \AA$ [57]. The reduced number of $\mathrm{Kr}$ neighbors observed can be easily explained by size effect of the $\mathrm{Kr}$ clusters. For nanometer-sized aggregates the contribution of the 
(a)

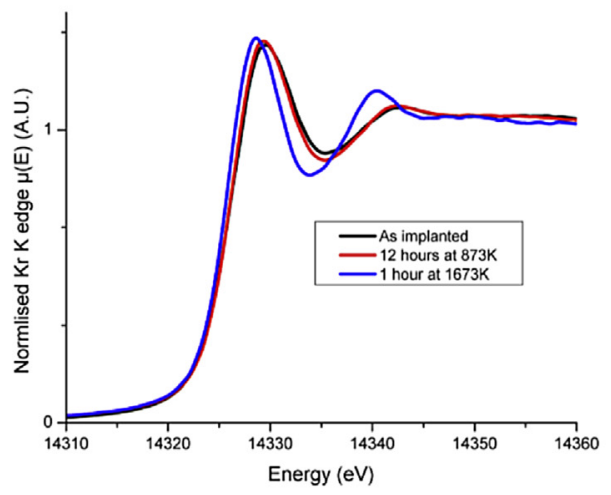

(b)

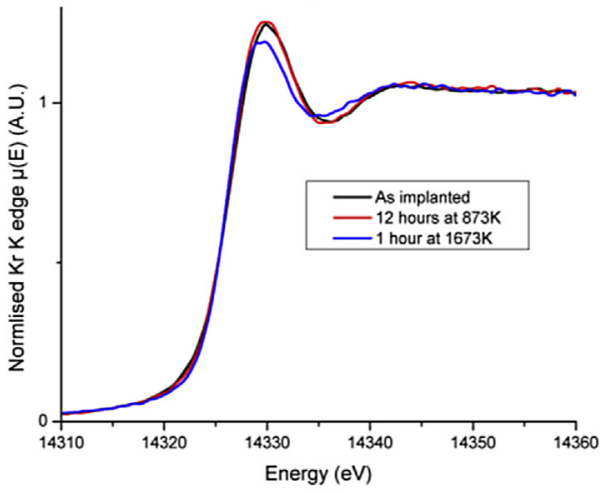

Fig. 2. Evolution of XANES spectra collected at $15 \mathrm{~K}$ (a) and $300 \mathrm{~K}$ (b) on 8 at.\% Kr-implanted samples (conditions A) as a function of annealing conditions.

Table 2

Experimental XANES values observed for Kr-implanted samples (conditions A). The uncertainty on energy determination is $0.2 \mathrm{eV}$.

\begin{tabular}{|c|c|c|c|c|}
\hline Sample & Temperature (K) & Threshold $\left(\mathrm{E}_{0}\right)$ position $(\mathrm{eV})$ & Second peak maximum $(\mathrm{eV})$ & Difference $\Delta \mathrm{E}(\mathrm{eV})$ \\
\hline \multirow[t]{2}{*}{ As-implanted } & 15 & 14326.5 & 14343.0 & 16.5 \\
\hline & 300 & 14326.4 & - & - \\
\hline \multirow[t]{2}{*}{$873 \mathrm{~K}-12 \mathrm{~h}$} & 15 & 14326.4 & 14342.7 & 16.3 \\
\hline & 300 & 14326.4 & - & - \\
\hline \multirow[t]{2}{*}{$1673 \mathrm{~K}-1 \mathrm{~h}$} & 15 & 14325.9 & 14340.7 & 14.8 \\
\hline & 300 & 14326.1 & - & - \\
\hline
\end{tabular}

krypton atoms located in the outer shell of the Kr particles becomes significant. The later are partially surrounded by matrix atoms and consequently reduces the number of $\mathrm{Kr}$ atoms present in their first coordination sphere. As the cubic symmetry around $\mathrm{Kr}$ atoms expected for a fcc structure is confirmed by XANES spectrum, the mean aggregate size can be deduced. Similarly of what it is observed in studies on spent fuels [7] and ion-irradiated $\mathrm{UO}_{2}$ samples [11,12], a spherical geometry of the $\mathrm{Kr}$ aggregates is assumed. The small $\mathrm{N}$ value suggests that the cavity radius is ranging between 3.62(2) $\AA$ and 5.12(3) A (fcc lattice parameter value calculated using the $\mathrm{Kr}-\mathrm{Kr}$ distance) because for a larger radius than the lattice parameter a number of neighbors equals to at least 6 would be expected. Furthermore, the reduced 3.62(2) $\AA$ $\mathrm{Kr}-\mathrm{Kr}$ distances compared to the $4.00 \AA$ value expected for an unstressed $\mathrm{Kr}$ crystal at $25 \mathrm{~K}$, clearly shows that $\mathrm{Kr}$ bubbles are

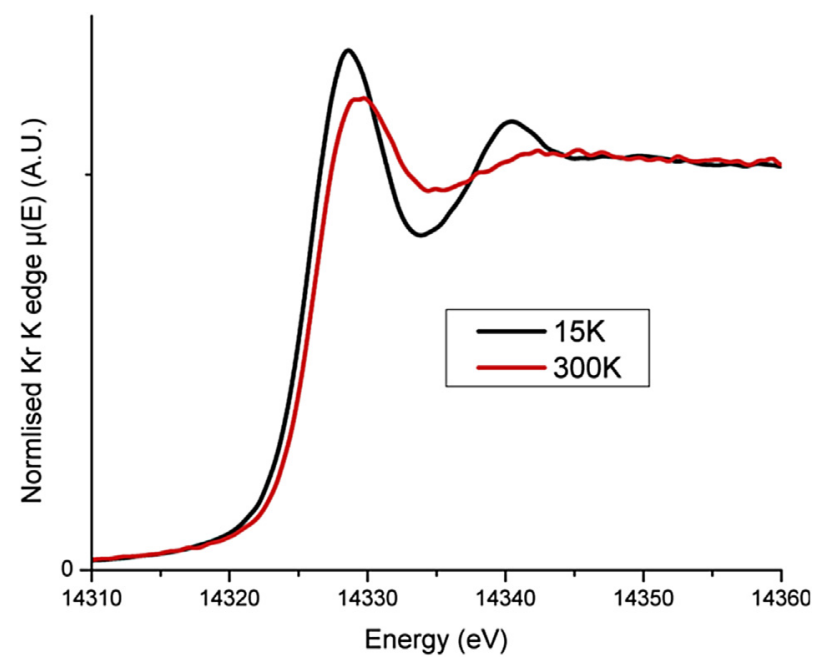

Fig. 3. Comparison of XANES spectra collected at 15 and $300 \mathrm{~K}$ on 8.0 at.\% sample (conditions A) annealed at $1673 \mathrm{~K}$ for one hour. pressurized in agreement with the XANES results suggesting that $\mathrm{Kr}$ nano-aggregates are solid at room temperature.

A $12 \mathrm{~h}$-thermal treatment at $873 \mathrm{~K}$ induced an increase in the length of $\mathrm{Kr}-\mathrm{Kr}$ bonds to $3.67(2) \AA$ but the coordination number remained equal to $4.9(5)$. The nanometer sized bubbles observed for the as-implanted sample remained pressurized. Only a slight decrease in their internal pressure was induced by this annealing condition which is consistent with XANES observations that showed no difference between spectra at 15 and $300 \mathrm{~K}$.

The results obtained after thermal treatment at $1673 \mathrm{~K}$ of $1 \mathrm{~h}$ showed a significant modification of the $\mathrm{Kr}$ local environment. The $\mathrm{Kr}-\mathrm{Kr}$ bond distance is equal to $4.00(2) \AA$ and an oxygen coordination shell is observed with $0.5(5)$ atoms at 2.94(2) Å. The distance of $4.00(2) \AA ̊$ between $\mathrm{Kr}$ atoms corresponds to the value observed for an unstressed solid $\mathrm{Kr}$ crystal at $25 \mathrm{~K}$ [57]. Furthermore, the Debye-Waller value is rather low $\left(0.008(2) \AA^{2}\right)$ which shows that highly ordered solid $\mathrm{Kr}$ is present. Nevertheless, each krypton atom was surrounded by only 3.0(5) Kr. In addition, XANES spectra collected at 15 and $300 \mathrm{~K}$ indicate a change in the physical state (solid state to gas) of the $\mathrm{Kr}$ aggregates is taking place between these two temperatures. This would suggest that a large portion of krypton atoms is now located inside cavities only partially filled with $\mathrm{Kr}$ atoms. The $\mathrm{Kr}$ density inside these cavities is sufficiently low to ensure that the krypton trapped inside is in a gaseous state at room temperature. Such observation explains the absence of internal pressure observed at $15 \mathrm{~K}$. Moreover, the $\mathrm{Kr}-\mathrm{O}$ coordination shell observed shows that the solid $\mathrm{Kr}$ aggregates are bound to the $\mathrm{UO}_{2}$ matrix which indicates that gaseous krypton trapped in the cavities at room temperature precipitate on their internal surface at $15 \mathrm{~K}$. However, the presence of pressurized nanometer sized aggregates is still observed in the XANES spectrum at $300 \mathrm{~K}$. A bi modal distribution of cavities is then present in the sample after such annealing conditions. 
(a)

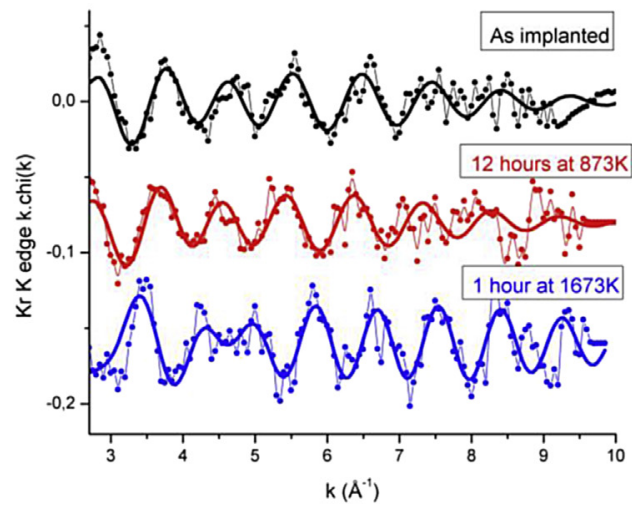

(b)

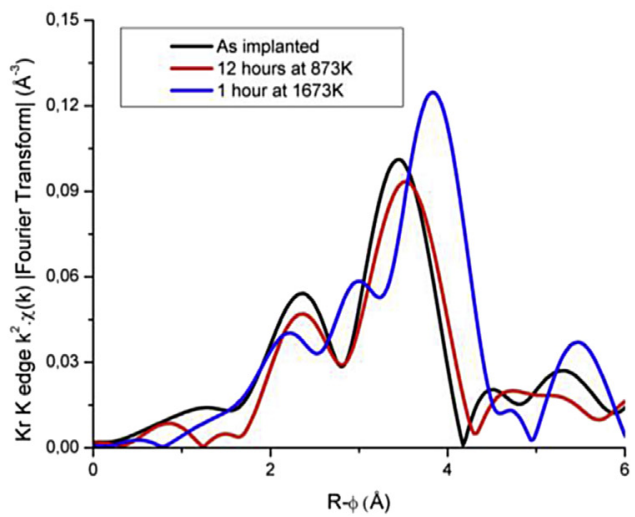

Fig. 4. EXAFS spectra (a) and their Fourier transforms (b) obtained for samples implanted using conditions A as a function of thermal treatments.

Table 3

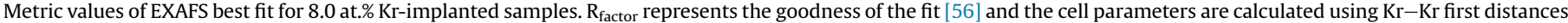
by assuming a fcc structure.

\begin{tabular}{|c|c|c|c|c|c|c|}
\hline Thermal treatment & Element & $\mathrm{R}(\AA)$ & $\mathrm{N}$ & $\sigma^{2}\left(\AA^{2}\right)$ & $\mathrm{R}_{\text {factor }}$ & Cell parameter $(\AA)$ \\
\hline (as implanted) & $\mathrm{Kr}$ & $3.62(2)$ & $4.8(5)$ & $0.021(2)$ & 0.01 & $5.12(3)$ \\
\hline $873 \mathrm{~K}-12 \mathrm{~h}$ & $\mathrm{Kr}$ & $3.67(2)$ & $4.9(5)$ & $0.021(2)$ & 0.01 & $5.19(3)$ \\
\hline \multirow[t]{2}{*}{$1673 \mathrm{~K}-1 \mathrm{~h}$} & 0 & $2.94(2)$ & $0.5(5)$ & $0.012(5)$ & & \\
\hline & $\mathrm{Kr}$ & $4.00(2)$ & $3.0(5)$ & $0.008(2)$ & 0.02 & $5.66(3)$ \\
\hline
\end{tabular}

\subsection{Results on 0.5 at.\% Kr as-implanted samples (conditions $B \& C$ )}

\subsubsection{XANES/EXAFS results}

As detailed in Table 1, the B and C implantation conditions lead to the same krypton local concentration at the distribution maximum: 0.5 at.\% but in one case the krypton distribution is centered at $300 \mathrm{~nm}$ (B) whereas the second is centered at $1200 \mathrm{~nm}$ (C). The HERFD-XANES spectra collected at 15 and $300 \mathrm{~K}$ on these two samples are compared in Fig. 5.

No difference between the spectra collected at these two temperatures can be observed, indicating no evolution of the $\mathrm{Kr}$ local environment. Furthermore, the HERFD-XANES spectra of the two samples are very similar and no white line corresponding to $\mathrm{Kr}$ aggregates is observed which is similar to Ito et al. [22] where $\mathrm{Kr}$ atoms were only bonded to carbon atoms. By analogy, the XANES spectra obtained would suggest that $\mathrm{Kr}$ atoms are bonded only to $\mathrm{UO}_{2}$ matrix atoms.
The EXAFS spectra and their Fourier transforms are given in Fig. 6. As in case of HERFD-XANES, almost similar spectra are observed for both samples. The results of the fit are given in Table 4 .

The exploitation of EXAFS data shows no $\mathrm{Kr}-\mathrm{Kr}$ bond and an almost identical local environment for both samples: 3.8(3) oxygen atoms at 2.86(2) Å and uranium atoms at 3.15(2) $\AA$ and 3.57(3) $\AA$, respectively. Considering the uncertainties on the coordination numbers $(\mathrm{N})$, inter-atomic distances $(\mathrm{R})$ and Debye-Waller factor $\left(\sigma^{2}\right)$ (see Table 4$)$, the differences lie only on the second shell: $1.0(5)$ U atom with $\sigma^{2}=0.008(2) \AA^{2}$ and 2.1(5) U atoms with $\sigma^{2}=0.008(2)$ $\AA^{2}$ for samples B and C, respectively.

These results confirmed the hypothesis suggested by the HERFD-XANES results: the XAS signal is due to $\mathrm{Kr}$ atoms bound to the matrix atoms. Therefore, krypton atoms are likely to be located within lattice defects of the $\mathrm{UO}_{2}$ fcc structure. (a)

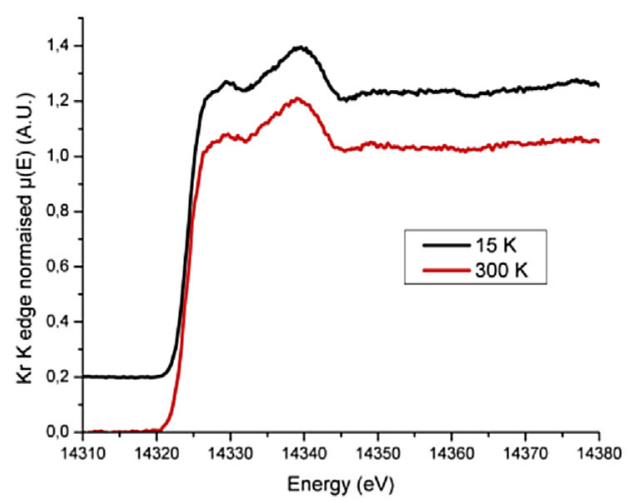

(b)

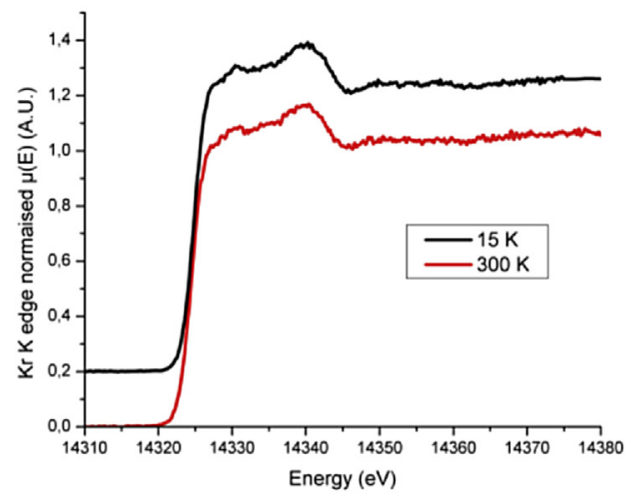

Fig. 5. HERFD-XANES spectra collected at $15 \mathrm{~K}$ and $300 \mathrm{~K}$ for implantation conditions $\mathrm{B}$ (a) and $\mathrm{C}$ (b). 
(a)

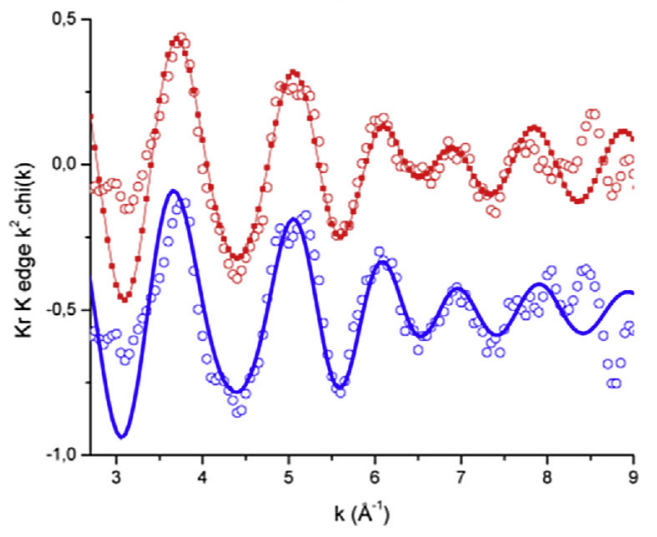

(b)

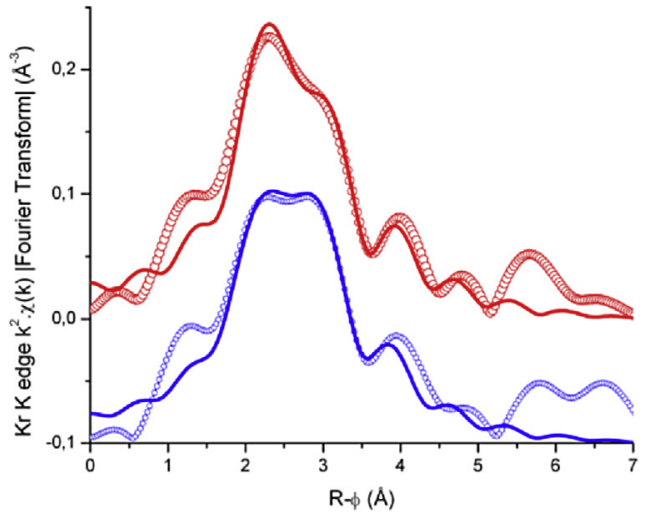

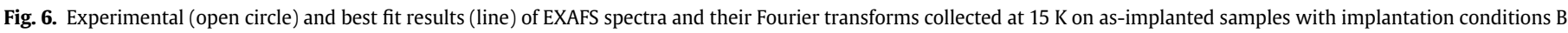
(red) and C (blue).(For interpretation of the references to color in this figure legend, the reader is referred to the web version of this article.)

Table 4

Metric values of EXAFS best fit results for as-implanted sample (N: Coordination number, R: inter-atomic distance, $\sigma^{2}$ : Debye-Waller factor).

\begin{tabular}{lllll}
\hline Sample & Element & $\mathrm{N}$ & $\mathrm{R}(\AA)$ & $\sigma^{2}\left(\AA^{2}\right)$ \\
\hline As-implanted B & $\mathrm{O}$ & $3.8(4)$ & $2.86(2)$ & $.0220(5)$ \\
& $\mathrm{U}$ & $1.0(5)$ & $3.16(2)$ & $.008(1)$ \\
& $\mathrm{U}$ & $1.5(5)$ & $3.59(3)$ & $.032(5)$ \\
& Global parameter & $\Delta \mathrm{E}_{0}=3.0(5)$ & & \\
& $\mathrm{R}_{\text {factor }}$ & $0.009(\mathrm{R}$-space $)-0.06(\mathrm{k}$-space $)$ \\
As-implanted C & $\mathrm{O}$ & $3.8(3)$ & $2.87(2)$ & $.0260(5)$ \\
& $\mathrm{U}$ & $2.1(5)$ & $3.14(2)$ & $.014(2)$ \\
& $\mathrm{U}$ & $2.3(5)$ & $3.56(3)$ & $.033(2)$ \\
& Global parameters & $\Delta \mathrm{E}_{0}=4.2(5)$ & & \\
& $\mathrm{R}_{\text {factor }}$ & $0.01(\mathrm{R}-\mathrm{space})-0.09(\mathrm{k}-$ & \\
& & space $)$ & & \\
\hline
\end{tabular}

\subsection{2. $D F T+U$ calculation results}

The goal of these calculations was to evaluate the most stable location of the $\mathrm{Kr}$ atom in the $\mathrm{UO}_{2}$ lattice and the associated distortion of the local environment. The DFT $+U$ calculations were performed for elementary defects and small clusters of point defects. The considered elementary defects were the oxygen and uranium vacancies (noted $\mathrm{V}_{\mathrm{U}}$ and $\mathrm{V}_{\mathrm{O}}$ ) and the octahedral interstitial site in the fluorite fcc structure. The Schottky defects which consist in the association of one uranium vacancy first neighbored to two oxygen vacancies $\left(\mathrm{V}_{\mathrm{U}}+2 \mathrm{~V}_{\mathrm{O}}\right)$ were considered. Three configurations are possible which correspond to the (100), (110) and (111) directions of the oxygen vacancies and are named BSD1, BSD2 and BSD3, respectively (BSD: Bound Schottky Defect). Finally, the U-O di-vacancy $\left(\mathrm{V}_{\mathrm{U}}+\mathrm{V}_{\mathrm{O}}\right)$, the $\mathrm{U}-\mathrm{U}$ di-vacancy $\left(2 \mathrm{~V}_{\mathrm{U}}\right)$, the tri-vacancy consisting of two uranium vacancies and one oxygen vacancy $\left(2 \mathrm{~V}_{\mathrm{U}}+\mathrm{V}_{\mathrm{O}}\right)$ and the quadri-vacancy with two uranium vacancies and two oxygen vacancies $\left(2 \mathrm{~V}_{\mathrm{U}}+2 \mathrm{~V}_{\mathrm{O}}\right)$ were also considered.

It is known that in semi-conductors or insulators point defects and clusters very often bear a charge that must be taken into account in the calculations. The methodology used here was the same as in Vathonne et al. [58]. In this study, it was found that the most stable charged state of lattice defects in $\mathrm{UO}_{2}$ are consistent with a strongly ionic system: $V_{U}^{4-}, V_{O}^{2+},\left(V_{U}+V_{O}\right)^{2-},\left(2 V_{U}+V_{O}\right)^{6-}$, $\left(2 V_{U}+2 V_{O}\right)^{4-}$ and $\left(2 V_{U}\right)^{8-}$ with Fermi level taken in the middle of the band gap. The three Schottky defects were found neutral. These results show a strong ionic character for $\mathrm{UO}_{2}$.

The formation energy of each defect was calculated as follows:
$E_{f}\left(V_{x}, q\right)=E_{\text {tot }}\left(V_{x}, q\right)-n_{O} \mu_{O}-n_{U} \mu_{U}+q \mu_{e}+E_{\text {corr }}$

where $E_{\text {tot }}\left(V_{x}, q\right)$ is the total energy of the supercell, $n_{O}$ and $n_{U}$ are the number of oxygen and uranium atoms in the cell, $\mu_{O}$ and $\mu_{U}$ are the chemical potential of the oxygen and uranium atoms in $\mathrm{UO}_{2}$ as calculated in Ref. [58], $q$ is the charge of the defect, $\mu_{e}$ is the electron chemical potential which varies from the bottom to the top of the band, and $E_{\text {Corr. }}$ are the corrections used for charged supercells.

The solution energy which corresponds to the insertion of $\mathrm{Kr}$ in a perfect lattice was calculated as follows:

$E_{\text {sol }}\left(V_{x}^{K r}, q\right)=E_{\text {tot }}\left(V_{x}^{K r}, q\right)-n_{O} \mu_{O}-n_{U} \mu_{U}+n_{K r} \mu_{K r}+q \mu_{e}$

Where $n_{K r}$ correspond to the number of krypton atoms in the cell and $\mu_{K r}$ is the chemical potential of the krypton atom. Finally we obtained the incorporation energy which is the energy necessary to incorporate $\mathrm{Kr}$ in a pre-existing defect from the difference of the solution energy and the formation energy:

$E_{\text {inc }}\left(V_{x}^{K r}, q\right)=E_{\text {sol }}\left(V_{x}^{K r}, q\right)-E_{f}\left(V_{x}, q\right)$

The calculation results are given in Table 5, for which the Fermi level is taken in the middle of the band gap.

Based on the values shown in Table 5 , the most stable location for the $\mathrm{Kr}$ atoms would be the quadri-vacancy $\left(2 \mathrm{~V}_{\mathrm{U}}+2 \mathrm{~V}_{\mathrm{O}}\right)^{4-}$ with an incorporation energy equal to $0.3 \mathrm{eV}$. The neutral BSD1 is the second most favorable incorporation site with an incorporation energy of $0.6 \mathrm{eV}$. A few more sites exhibiting relatively low incorporation energies are also probable trapping sites for krypton, like the $\left(2 V_{U}+V_{O}\right)^{6-},\left(V_{U}+V_{O}\right)^{2-}$ and BSD2 sites with incorporation energies equal to $1.0,1.2$ and $1.2 \mathrm{eV}$, respectively.

The atomic positions obtained with DFT $+U$ calculations were used to determine the local environment of the $\mathrm{Kr}$ atom in the $\mathrm{UO}_{2}$ lattice. The results are given in Table 6, Table 7 and Table 8 for small defects, Schottky defects and defect clusters containing two uranium vacancies, respectively. The distances calculated from the central krypton atom are given up to $5 \AA$ A or the second $\mathrm{Kr}-\mathrm{U}$ coordination. Only the krypton-oxygen distances shorter or equal to 3 A are reported. ${ }^{1}$

Based on these results, interstitial, $\mathrm{O}$ vacancy $\left(\mathrm{V}_{\mathrm{O}}\right)^{2+}, \mathrm{U}$ vacancy $\left(\mathrm{V}_{\mathrm{U}}\right)^{4-}$ and $\mathrm{U}$ di-vacancy $\left(2 \mathrm{~V}_{\mathrm{U}}\right)^{8-}$ can be discarded as incorporation

\footnotetext{
${ }^{1}$ Coordination shells separated by less than $0.02 \AA$ have been grouped.
} 
Table 5

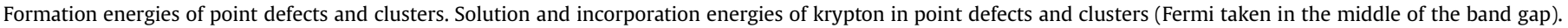

\begin{tabular}{|c|c|c|c|}
\hline Considered defects & Formation energies $\mathrm{E}_{\mathrm{f}}(\mathrm{eV})$ & Solution energies $\mathrm{E}_{\mathrm{sol}}(\mathrm{eV})$ & Incorporation energies $E_{\text {inc }}(\mathrm{eV})$ \\
\hline Interstitial & I & 6.5 & 6.5 \\
\hline$\left(V_{U}\right)^{4-}$ & 2.6 & 4.9 & 2.3 \\
\hline$\left(V_{O}\right)^{2+}$ & 1.3 & 6.3 & 5.0 \\
\hline$\left(V_{U}+V_{O}\right)^{2-}$ & 2.0 & 3.2 & 1.2 \\
\hline Neutral BSD1 & 3.3 & 3.9 & 0.6 \\
\hline Neutral BSD2 & 2.5 & 3.7 & 1.2 \\
\hline Neutral BSD3 & 2.6 & 4.1 & 1.5 \\
\hline$\left(2 V_{U}\right)^{8-}$ & 5.8 & 8.0 & 2.2 \\
\hline$\left(2 V_{U}+V_{O}\right)^{6-}$ & 4.2 & 5.2 & 1.0 \\
\hline$\left(2 V_{U}+2 V_{O}\right)^{4-}$ & 3.4 & 3.7 & 0.3 \\
\hline
\end{tabular}

Table 6

Local environments of krypton atom in small defects obtained by DFT $+U$ calculations.

\begin{tabular}{|c|c|c|c|c|c|c|c|c|}
\hline \multicolumn{3}{|c|}{ Interstitial } & \multicolumn{3}{|c|}{$\left(\mathrm{V}_{\mathrm{O}}\right)^{2+}$} & \multicolumn{3}{|c|}{$\left(\mathrm{V}_{\mathrm{U}}\right)^{4-}$} \\
\hline $\mathrm{N}$ & Atom & Distance $(\AA)$ & $\mathrm{N}$ & Atom & Distance $(\AA)$ & $\mathrm{N}$ & Atom & Distance $(\AA ̊)$ \\
\hline 8 & $\mathrm{O}$ & 2.61 & 2 & $\mathrm{O}$ & 2.79 & 8 & $\mathrm{O}$ & 2.85 \\
\hline 2 & $\mathrm{U}$ & 2.91 & 6 & $\mathrm{U}$ & 2.80 & 8 & $\mathrm{U}$ & 3.96 \\
\hline 4 & $\mathrm{U}$ & 2.95 & 4 & $\mathrm{O}$ & 2.84 & & & \\
\hline 4 & $\mathrm{U}$ & 4.84 & 12 & $\mathrm{U}$ & 4.61 & & & \\
\hline
\end{tabular}

sites in the experimental results as their local environments do not match the EXAFS results (see Table 4). It is consistent with the fact that these defects present the highest incorporation energy values (see Table 5). Only the BSD1 and the tri-vacancy $\left(2 V_{U}+V_{O}\right)^{6-}$ exhibit 2 coordination shells of $U$ atoms with $\mathrm{Kr}-\mathrm{U}$ distances shorter than $4 \AA$. These two defects with incorporation energies of $0.6 \mathrm{eV}$ for BSD1 and $1.0 \mathrm{eV}$ for $\left(2 \mathrm{~V}_{\mathrm{U}}+\mathrm{V}_{\mathrm{O}}\right)^{6-}$ are the second and the third most probable incorporation sites. The BSD1 is the closest environment compared to EXAFS results with four oxygen atoms at $2.94 \AA$ and uranium atoms at $3.17 \AA$ and $3.71 \AA$. For the quadrivacancy $\left(2 V_{U}+2 V_{O}\right)^{4-}$, which is the most favorable incorporation site accordingly to the calculation $\left(E_{\text {incor }}=0.3 \mathrm{eV}\right)$, the local

Table 7

Local environments of krypton atoms in Schottky defects obtained by DFT $+U$ calculations.

\begin{tabular}{|c|c|c|c|c|c|c|c|c|}
\hline \multicolumn{3}{|c|}{ BSD1 } & \multicolumn{3}{|c|}{ BSD2 } & \multicolumn{3}{|c|}{ BSD3 } \\
\hline $\mathrm{N}$ & Atom & Distance $(\AA)$ & $\mathrm{N}$ & Atom & Distance $(\AA)$ & $\mathrm{N}$ & Atom & Distance $(\AA)$ \\
\hline 4 & $\mathrm{O}$ & 2.94 & 2 & $\mathrm{O}$ & 2.79 & 6 & $\mathrm{O}$ & 2.87 \\
\hline 1 & $\mathrm{U}$ & 3.17 & 4 & $\mathrm{U}$ & 3.73 & 6 & $\mathrm{U}$ & 3.98 \\
\hline 4 & $\mathrm{U}$ & 3.71 & 2 & $\mathrm{U}$ & 4.00 & 6 & $\mathrm{U}$ & 4.02 \\
\hline 1 & $\mathrm{U}$ & 4.10 & 2 & $\mathrm{U}$ & 4.06 & & & \\
\hline 1 & $\mathrm{U}$ & 4.13 & 4 & $\mathrm{U}$ & 4.28 & & & \\
\hline 4 & $\mathrm{U}$ & 4.45 & 1 & $\mathrm{U}$ & 4.98 & & & \\
\hline 1 & $\mathrm{U}$ & 4.76 & & & & & & \\
\hline 1 & U & 4.91 & & & & & & \\
\hline
\end{tabular}

environment observed is very far from the EXAFS results: no oxygen atoms located at less than $3 \AA$ and a first $\mathrm{Kr}-\mathrm{U}$ distance equal to $3.54 \AA$ is from far too long compared to the 3.15(2) A experimentally measured.

To validate this interpretation, atomic coordinates obtained for the various calculated defects were used as input data in the XANES $a b$ initio code FDMNES. The results obtained for tri-vacancy $\left(2 \mathrm{~V}_{\mathrm{U}}+\mathrm{V}_{\mathrm{O}}\right)^{6-}$, quadri-vacancy $\left(2 \mathrm{~V}_{\mathrm{U}}+2 \mathrm{~V}_{\mathrm{O}}\right)^{4-}$ and BSD1 are compared with experimental data collected for the 0.5 at.\% $\mathrm{Kr}$ asimplanted sample in Fig. 7. As indicated by the black arrow in Fig. 7, the main features in experimental spectra located at $+1.5 \mathrm{eV},+5.0 \mathrm{eV}$ and $+15.0 \mathrm{eV}$ after the threshold are reproduced only for BSD1. A fit of the experimental spectrum was attempted using linear combination of the spectra obtained for the different defects considered. No improvement in the agreement was observed and the best result was obtained with the spectrum corresponding to the BSD1. The differences between the two spectra shown in Fig. 7c can be then attributed to the structural disorder around krypton atoms illustrated by the rather high Debye-Waller factor values of the different coordination shells (see Table 4). The mean displacement of $\mathrm{Kr}, \mathrm{U}$ and $\mathrm{O}$ atoms around their atomic positions was not considered in the FDMNES calculations.

XAS and DFT $+U$ results are in very good agreement and we can conclude that the most stable location of $\mathrm{Kr}$ atoms in $\mathrm{UO}_{2}$ lattice is a neutral Schottky defect with O vacancies aligned along the (100) direction (BSD1). Furthermore, the depth location of $\mathrm{Kr}$ atoms at 300 or $1200 \mathrm{~nm}$ from the surface does not influence the krypton behavior, as the same local environment was observed for both implantation conditions (B and C).

\subsection{Results on annealed 0.5 at.\% $\mathrm{Kr}$ samples}

The 0.5 at.\% samples (conditions B and C) were thermally treated during $4 \mathrm{~h}$ at $1673 \mathrm{~K}$ and for $12 \mathrm{~h}$ at $1273 \mathrm{~K}$, respectively. For these two samples, the signal to noise ratio was insufficient to extract EXAFS oscillations from the raw data, even after several hours of data collection. Consequently, only HERFD-XANES results are presented.

Table 8

Local environments of krypton atoms in clusters obtained by DFT $+U$ calculations.

\begin{tabular}{|c|c|c|c|c|c|c|c|c|c|c|c|}
\hline \multicolumn{3}{|c|}{$\left(\mathrm{V}_{\mathrm{U}}+\mathrm{V}_{\mathrm{O}}\right)^{2-}$} & \multicolumn{3}{|c|}{$\left(2 V_{U}\right)^{8-}$} & \multicolumn{3}{|c|}{$\underline{\left(2 V_{U}+V_{O}\right)^{6-}}$} & \multicolumn{3}{|c|}{$\left(2 \mathrm{~V}_{\mathrm{U}}+2 \mathrm{~V}_{\mathrm{O}}\right)^{4-}$} \\
\hline $\mathrm{N}$ & Atom & Distance $(\AA)$ & $\mathrm{N}$ & Atom & Distance $(\AA)$ & $\mathrm{N}$ & Atom & Distance $(\AA)$ & $\mathrm{N}$ & Atom & Distance $(\AA)$ \\
\hline 3 & $\mathrm{O}$ & 2.82 & 6 & $\mathrm{O}$ & 2.84 & 1 & $\mathrm{O}$ & 2.76 & 2 & $\mathrm{U}$ & 3.54 \\
\hline 3 & $\mathrm{U}$ & 3.33 & 2 & $\mathrm{O}$ & 3.00 & 1 & $\mathrm{U}$ & 3.21 & 2 & $\mathrm{U}$ & 4.33 \\
\hline 2 & $\mathrm{U}$ & 4.09 & 4 & $U$ & 3.86 & 1 & $\mathrm{U}$ & 3.96 & 1 & $\mathrm{U}$ & 4.38 \\
\hline 2 & $\mathrm{U}$ & 4.11 & 1 & $\mathrm{U}$ & 3.90 & 2 & $\mathrm{U}$ & 4.37 & & & \\
\hline 2 & $\mathrm{U}$ & 4.13 & 1 & $\mathrm{U}$ & 3.92 & 1 & $\mathrm{U}$ & 4.54 & & & \\
\hline 2 & $\mathrm{U}$ & 4.63 & 4 & $\mathrm{U}$ & 4.05 & & & & & & \\
\hline 1 & $\mathrm{U}$ & 4.66 & & & & & & & & & \\
\hline
\end{tabular}


(a)

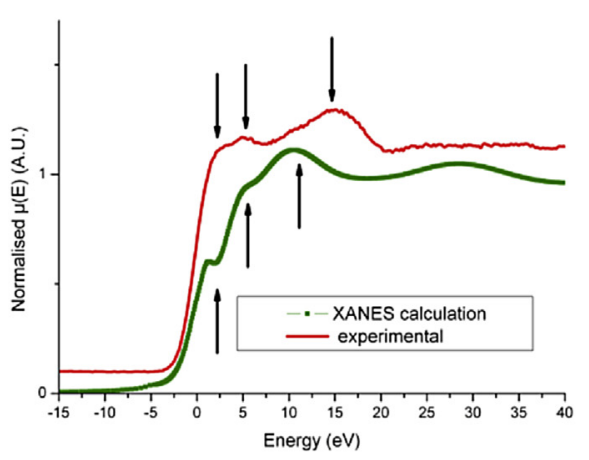

(c)

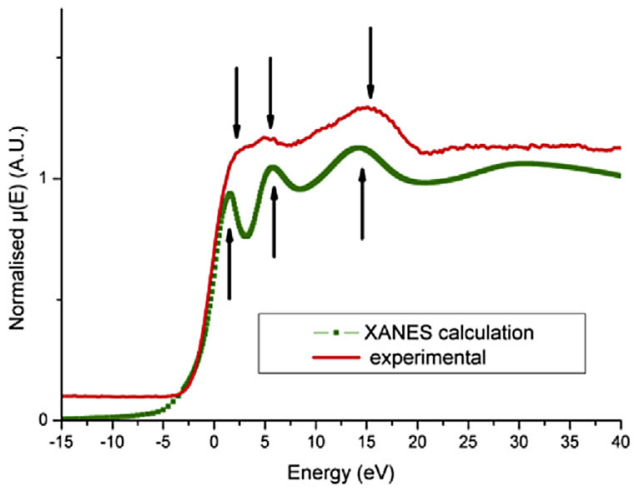

(b)

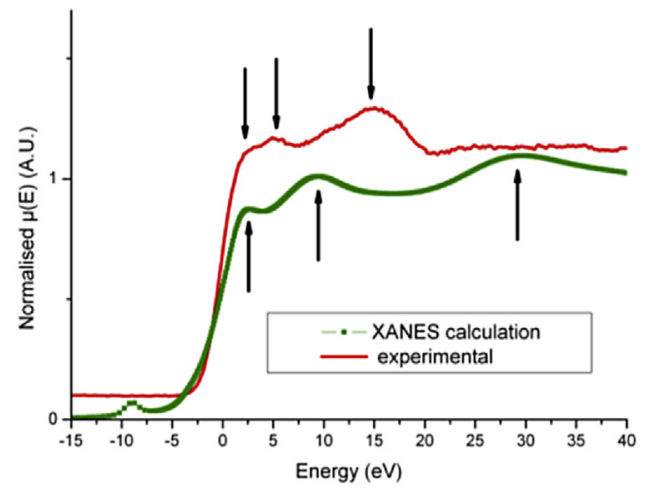

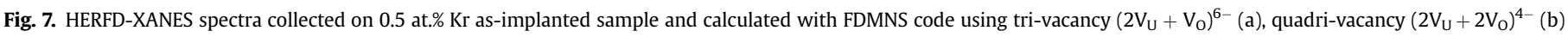
and BSD1 (c) geometry determined by DFT $+U$ (experimental spectra were shifted for clarity).

\subsubsection{After $4 \mathrm{~h}$ annealing at $1673 \mathrm{~K}$}

As illustrated by Fig. 8, a 4 h thermal treatment at $1673 \mathrm{~K}$ induces a complete modification of the HERFD-XANES signal. After annealing, the spectrum collected on the annealed sample exhibits the same feature as observed for samples with 8 at.\% Kr: an intense white line and a broad peak located at $15-17 \mathrm{eV}$ after the threshold. A complete modification of the $\mathrm{Kr}$ local environment was then

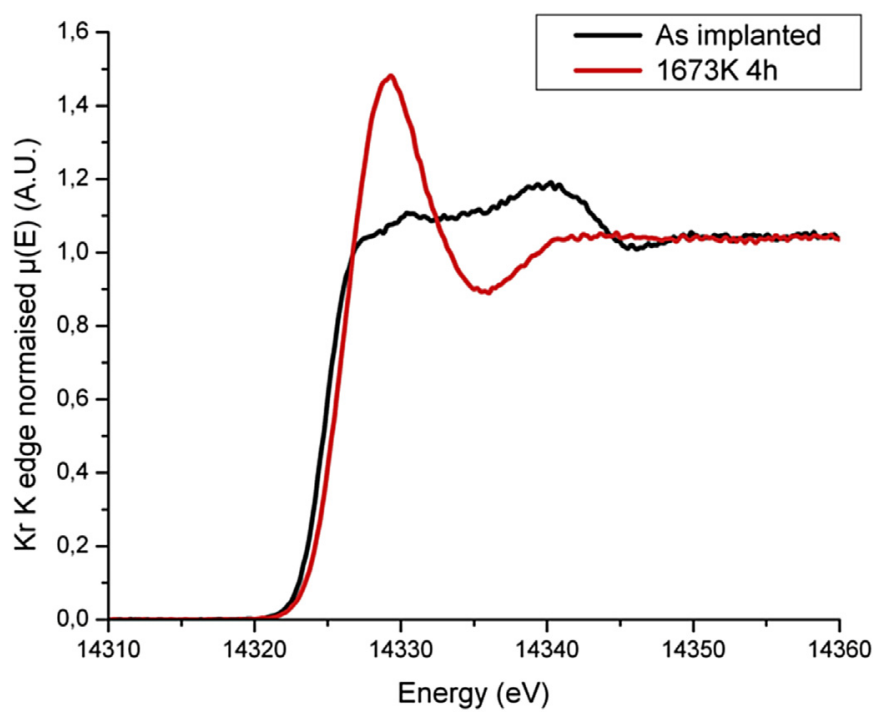

Fig. 8. HERFD-XANES spectra collected at $15 \mathrm{~K}$ on 0.5 at.\% as-implanted and annealed at $1673 \mathrm{~K}$ for four hours samples. induced by these annealing conditions.

As detailed in part I-1, the $\mathrm{Kr}$ atoms are surrounded by krypton atoms after annealing. As a consequence, such a thermal treatment induces a precipitation of $\mathrm{Kr}$ nano-aggregates. The comparison of the signals collected at $15 \mathrm{~K}$ and $300 \mathrm{~K}$ in Fig. 9a, shows a limited evolution between the two temperatures. This suggests that for a majority of $\mathrm{Kr}$ aggregates no modification of their physical state is observed between $15 \mathrm{~K}$ and $300 \mathrm{~K}$. The threshold and the white line maximum positions are given in Table 9. No modification in the threshold position is observed ( $14325.4 \mathrm{eV}$ ) and only a $0.4 \mathrm{eV}$ shift to lower energy between $300 \mathrm{~K}$ and $15 \mathrm{~K}$ is measured. Consequently, a majority of the $\mathrm{Kr}$ aggregates observed have a density sufficiently high to be in solid state at room temperature. To illustrate this observation, the spectra collected at $15 \mathrm{~K}$ is compared in Fig. 9b to XANES spectra collected on samples (A) annealed for $1 \mathrm{~h}$ at $1673 \mathrm{~K}$ (unstressed $\mathrm{Kr}$ aggregate) and for $12 \mathrm{~h}$ at $873 \mathrm{~K}$ (dense nano-clusters solid at $300 \mathrm{~K}$ ). The position of white line maximum (14329.2 eV) for sample $\mathrm{C}$ lies between those observed for samples A annealed at $1673 \mathrm{~K}(14328.4(2) \mathrm{eV})$ and at $873 \mathrm{~K}(14329.6(2) \mathrm{eV})$.

Nevertheless, an evolution is observed between $15 \mathrm{~K}$ and $300 \mathrm{~K}$ indicating that a small fraction of $\mathrm{Kr}$ aggregates observed at $15 \mathrm{~K}$ are gaseous at room temperature. As a consequence, the associated krypton atoms are located within cavities with a low gas density. Then a bi-modal distribution of $\mathrm{Kr}$ bubbles is present after such thermal treatment similarly to that was observed for a 8.0 at.\% $\mathrm{Kr}$ sample annealed at the same temperature. But, with a low $\mathrm{Kr}$ content ( 0.5 at.\%), only a small proportion of krypton atoms is located in "large" cavities. 
(a)

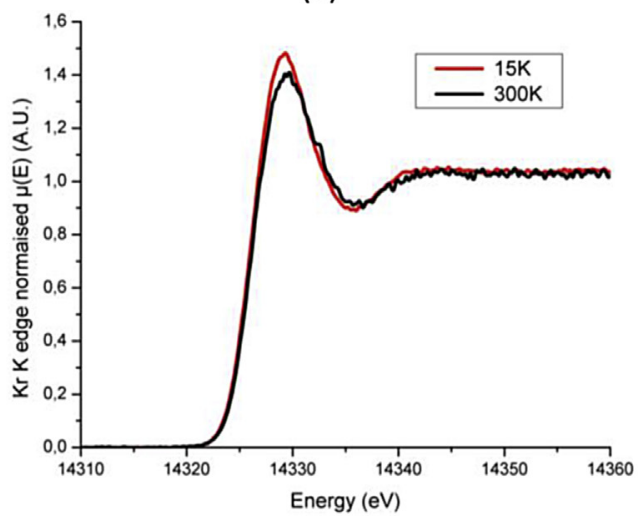

(b)

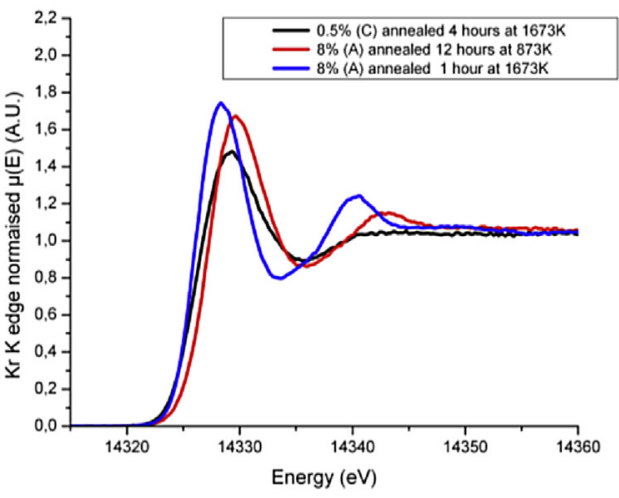

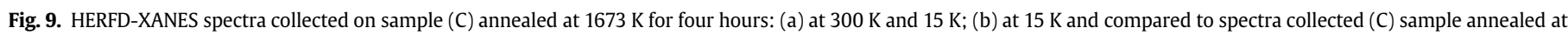
$873 \mathrm{~K}$ for twelve hours and at $1673 \mathrm{~K}$ for one hour.

Table 9

White line and threshold positions observed in HERFD-XANES spectra collected at 15 and $300 \mathrm{~K}$ on sample (C) annealed at $1673 \mathrm{~K}$ for four hours.

\begin{tabular}{lll}
\hline Temperature $(\mathrm{K})$ & Threshold $(\mathrm{eV})$ & White line maximum $(\mathrm{eV})$ \\
\hline 15 & 14326.4 & 14329.2 \\
300 & 14326.4 & 14329.6 \\
\hline
\end{tabular}

\subsubsection{After $12 \mathrm{~h}$ annealing at $1273 \mathrm{~K}$}

HERFD-XANES spectra collected at $15 \mathrm{~K}$ and $300 \mathrm{~K}$ on samples annealed at $1273 \mathrm{~K}$ for $12 \mathrm{~h}$ are shown in Fig. 10a. The differences between $15 \mathrm{~K}$ and $300 \mathrm{~K}$ spectra are negligible (compared to the signal to noise ratio), but compared to as-implanted sample (see Fig. 10b), a modification of the $\mathrm{Kr}$ local environment can be observed.

Beyond the white line, the spectra differs strongly from the signal observed for $\mathrm{Kr}$ aggregates like sample $\mathrm{C}$ annealed at $1673 \mathrm{~K}$ for $4 \mathrm{~h}$ (see Fig. 10b). As shown in Fig. 11, the HERFD-XANES spectra at $300 \mathrm{~K}$ can be reproduced with a linear combination of two experimental spectra:

- $26 \pm 2 \%$ of the spectra collected on as-implanted sample B and corresponds to $\mathrm{Kr}$ atoms located inside a Bound Schottky Defect 1 ,

- $74 \pm 2 \%$ of the spectra collected on 0.5 at.\% Kr-doped sample annealed at $1673 \mathrm{~K}$ for $4 \mathrm{~h}$ where $\mathrm{Kr}$ atoms are located only within dense nano-aggregates.

(a)

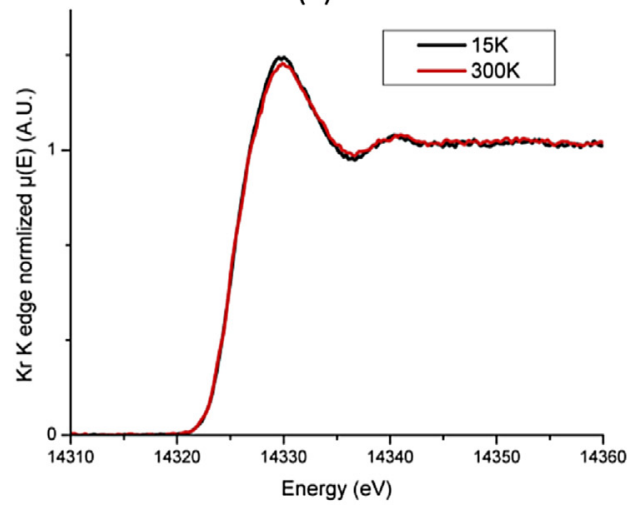

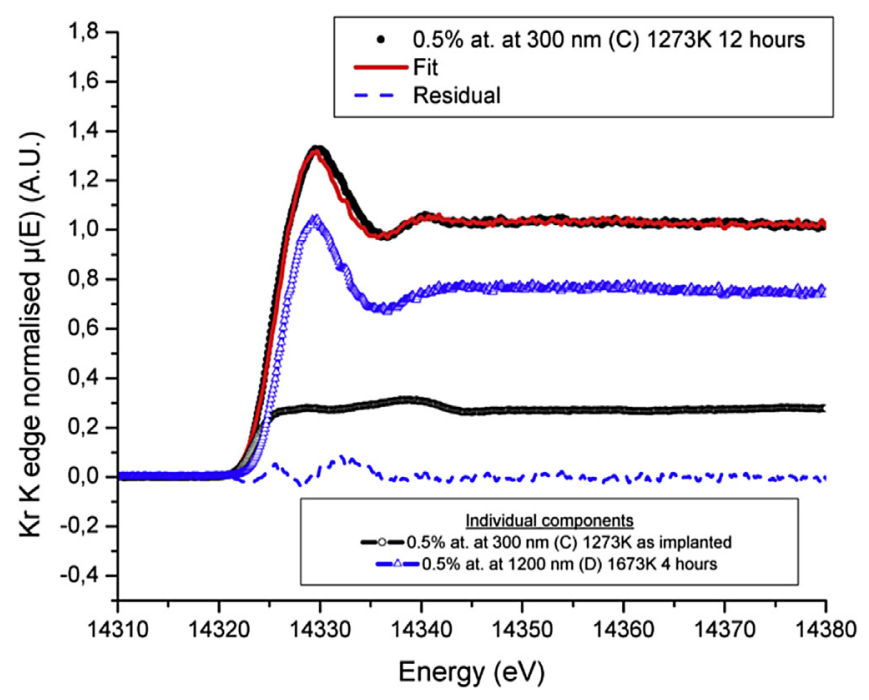

Fig. 11. Linear combination results performed on HERFD-XANES collected at $15 \mathrm{~K}$ on sample B annealed at $1273 \mathrm{~K}$ for twelve hours.

This result shows that after a thermal treatment at $1673 \mathrm{~K}$ for 12 h, $26 \pm 2 \%$ of implanted $\mathrm{Kr}$ atoms are located within BSD1 point defects. The remaining krypton amount $(74 \pm 2 \%$ ) precipitates as dense nano-aggregates.

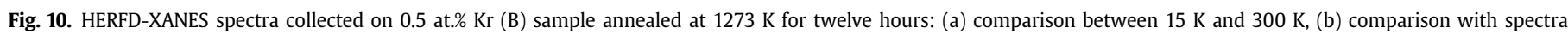
collected at $300 \mathrm{~K}$ on as-implanted and (C) annealed at $1673 \mathrm{~K}$ for four hours. 


\section{Discussion}

\section{1. $\mathrm{Kr}$ density/pressure}

The $\mathrm{Kr}$ density at $15 \mathrm{~K}$ within nano-aggregates for samples implanted with a fluence of $10^{17} \mathrm{Kr} \mathrm{cm}^{-2}$ (conditions A) can be estimated using the EXAFS results. A fcc structure of solid $\mathrm{Kr}$ can be assumed based on the similarity between the present XANES signal and the spectra obtained for solid $\mathrm{Kr}[16,17,22]$. The $\mathrm{Kr}-\mathrm{Kr}$ distances can be used to obtain both associated cell parameters and molar volumes allowing calculating the density within $\mathrm{Kr}$ nanoaggregates. The results are given in Table 10.

As no modification of XANES spectra was observed between $15 \mathrm{~K}$ and $300 \mathrm{~K}$, it suggests that values given in Table 10 are also valid at $300 \mathrm{~K}$. By using the equation of state determined by A. P. Jephcoat [59] with molar volume values given in Table 10, the calculated krypton pressure at $300 \mathrm{~K}$ within $\mathrm{Kr}$ nano-aggregates is 2.6(3) GPa and 2.0(2) GPa for as-implanted and annealed at $873 \mathrm{~K}$ for $12 \mathrm{~h}$ samples, respectively. The pressure values can also be estimated by comparing directly the values extracted from XANES (see Table 2) to those obtained by Polian et al. [16]. In this study the combination of XAS and XRD measurements on krypton volume encapsulated inside a diamond anvil cell allowed Polian et al. [16] to establish an equation of state linking pressure and $\Delta \mathrm{E}$ from XANES spectra. The 16.5(2) eV and 16.3(2) eV determined for the two samples then correspond to a pressure ranging between 2 and $3 \mathrm{GPa}$. This result is in agreement with the values determined using the $\mathrm{Kr}-\mathrm{Kr}$ distances measured with EXAFS and therefore validated the use of a $\mathrm{Kr}$ cell parameter calculated from experimental $\mathrm{Kr}-\mathrm{Kr}$ distance in the EOS.

Nevertheless, these pressure values are obtained using an EOS determined with pure $\mathrm{Kr}$ without taking into account the effect of the surrounding $\mathrm{UO}_{2}$ matrix (surface interaction for example). Murphy et al. [60] studied thermodynamics of xenon bubbles of $\sim 2 \mathrm{~nm}$ on diameter inside $\mathrm{UO}_{2}$ using classical molecular dynamics simulations. One of the associated conclusions was that for a Xe density ranging between $0.025 \mathrm{~mol} \mathrm{~cm}^{-3}$ and $0.054 \mathrm{~mol} \mathrm{~cm}^{-3}$, the matrix contribution to the internal pressure cannot be neglected. The experimental results obtained in the present study (see Table 10) lie in this range. As a consequence, the pressure inside the nano-aggregates might be under-estimated.

The densities observed inside the nano-aggregates in the present work are significantly higher $\left(28.5-30.3\right.$ at $\left.\mathrm{nm}^{-3}\right)$ than the $20.4 \pm 0.2$ at $\mathrm{nm}^{-3}$ deduced from XAS measurements in a $44.0 \mathrm{GW} \mathrm{d} \mathrm{t}{ }^{-1} \mathrm{UO}_{2}$ spent fuel [23]. However, a direct comparison to results detailed here remains limited as in such sample the krypton atoms are dissolved into Xe aggregates and the density estimated by the authors is based on the $\mathrm{Kr}-\mathrm{Xe}$ distance. Furthermore, it is relevant to note that the determined $\mathrm{Kr}-\mathrm{Xe}$ bond distance of 3.66(3) A is identical to that observed on the sample annealed at $873 \mathrm{~K}$ for $12 \mathrm{~h}$. The spent fuel sample [23] was extracted from the periphery of the fuel (RIM region) and therefore its temperature was relatively low upon irradiation $(<\sim 500 \mathrm{~K})$ [3]. The decrease in density observed after the $12 \mathrm{~h}$-annealing shows that a short range local rearrangement of the $\mathrm{UO}_{2}$ matrix around aggregates occurs during the thermal treatment.

\subsection{Comparison with xenon in $\mathrm{UO}_{2}$}

Previous studies performed on fresh $\mathrm{UO}_{2}$ implanted with xenon (2.0 and 8.0 at.\%) have also evidenced the presence of very dense nanometer sized xenon aggregates $[29,61]$. Their pressure was estimated to be 2.8(3) GPa for as-implanted sample and 2.0(3) GPa after an annealing at $873 \mathrm{~K}$ for $12 \mathrm{~h}$ under dry reducing atmosphere $\left(\mathrm{Ar}-5 \% \mathrm{H}_{2}\right)$. These pressure values obtained for $\mathrm{Xe}$ and $\mathrm{Kr}$ can be compared since pure gases EOS were used in both cases and no corrections of matrix effect were made. These values determined for xenon are identical to those obtained for krypton: 2.6(3) GPa (as implanted) and 2.0(3) GPa (annealed at $873 \mathrm{~K}$ for $12 \mathrm{~h}$ ). Furthermore, estimated mean size of Xe aggregates deduced from EXAFS analysis is the same: i.e. $\sim 1 \mathrm{~nm}$.

The estimated pressures were deduced from $\mathrm{Xe}-\mathrm{Xe}$ bond distances using the same methodology than used here and correspond to a Xe density of $4.9(1)$ and $4.7(1) \mathrm{g} \mathrm{cm}^{-3}$ or 22.6(3) and 21.4(3) at $\mathrm{nm}^{-3}$. These calculated values are in good agreement with the density range of $3.8-6 \mathrm{~g} \mathrm{~cm}^{-3}$ in $(\mathrm{Xe}+\mathrm{Kr}$ ) aggregates obtained by Thomas et al. $[9,10]$ on a $\mathrm{UO}_{2}$ sample irradiated at burn-up of $44.0 \mathrm{GW} \mathrm{d} \mathrm{t}^{-1}$. The $20.4 \pm 0.2$ at $\mathrm{nm}^{-3}$ value found by Degueldre et al. [23] is now in good agreement and can be used for a comparison as this RG density obtained on a $\mathrm{UO}_{2}$ sample irradiated at the same burnup is ruled by Xe (about 10 times more abundant than $\mathrm{Kr}$ ).

After a thermal treatment at high temperature $(\geq 1673 \mathrm{~K})$, a bimodal distribution of cavities containing Xe atoms was proposed by Martin et al. [29]. Thanks to the comparison between measurements on $\mathrm{Kr}$ performed at room temperature and $15 \mathrm{~K}$, this hypothesis can be confirmed as both a clear contribution of krypton located in partially filled larger cavities and the presence of krypton within dense nano-aggregates are detected. These results are also in good agreement with observations of Kashibe et al. [62] performed on spent fuels. The behavior of xenon and krypton at high concentration ( $\sim 8.0$ at.\%) in $\mathrm{UO}_{2}$ can be considered identical and the properties of these RG nano-aggregates are very close to those observed in $\mathrm{UO}_{2}$ spent fuel.

\section{3. $\mathrm{Kr}$ incorporation in the $\mathrm{UO}_{2}$ lattice}

The combination of EXAFS/XANES results and DFT $+U$ calculation shows that without thermal treatment and for a local concentration of 0.5 at.\%, the krypton atoms are predominantly located within neutral bound Schottky defects with oxygen vacancies aligned along the (100) direction (BSD1). This conclusion is in good agreement with previous theoretical electronic structure studies that involve empirical potentials [24], DFT $[25,26]$ or DFT $+U[26]$ showing that a pre-existing Schottky defect would be the most stable defect for $\mathrm{Kr}$ atoms. However, in these works no larger defect clusters like quadri-vacancy were considered. As shown in Table 5, the DFT $+U$ results indicate that the most stable incorporation site would consist in a quadri-vacancy $\left(2 \mathrm{~V}_{\mathrm{O}}+2 \mathrm{~V}_{\mathrm{U}}\right)^{4-}$. Nevertheless, the present results clearly demonstrate the contrary as the associated local environment around $\mathrm{Kr}$ atoms is in strong disagreement with XAS experimental results. As a consequence, unlike the BSD1, the quadri-vacancy $\left(2 \mathrm{~V}_{\mathrm{O}}+2 \mathrm{~V}_{\mathrm{U}}\right)^{4-}$ defect would not be effectively

Table 10

Krypton density inside nanometer-sized aggregates observed for samples implanted using conditions A.

\begin{tabular}{|c|c|c|c|c|c|c|}
\hline \multirow[t]{2}{*}{ Thermal treatment } & \multirow[t]{2}{*}{$\mathrm{Kr}-\mathrm{Kr}$ distance $(\AA ̊)$} & \multirow[t]{2}{*}{ Cell parameter $(\AA)$} & \multirow[t]{2}{*}{ Molar volume $\left(\mathrm{cm}^{3} \mathrm{~mol}^{-1}\right)$} & \multicolumn{3}{|l|}{ Kr density } \\
\hline & & & & $\left(\right.$ at $\left.\mathrm{nm}^{-3}\right)$ & $\left(\mathrm{mol} \mathrm{cm}{ }^{-3}\right)$ & $\left(\mathrm{g} \mathrm{cm}^{-3}\right)$ \\
\hline As-implanted & $3.62(2)$ & $5.12(3)$ & $20.2(3)$ & $29.8(5)$ & $.0495(8)$ & $4.15(7)$ \\
\hline $873 \mathrm{~K} 12 \mathrm{~h}$ & $3.67(2)$ & $5.19(3)$ & $21.0(3)$ & $28.6(5)$ & $0.0475(8)$ & $3.98(5)$ \\
\hline
\end{tabular}


created or not stable enough during the implantation process. Nevertheless, the good agreement between DFT + U and experiment was not obvious because during the implantation process the defects are continuously created within collision cascades. As shown by molecular dynamic simulations of collision cascades in $\mathrm{UO}_{2}, \sim 95 \%$ of defects are recombined after the cascade ( $20 \mathrm{ps}$ after the cascade) $[63,64]$. The remaining defects are vacancies clusters and interstitial loops as shown by TEM observations $[65,66]$. The EXAFS results show that $\mathrm{Kr}$ atoms are trapped within a neutral trivacancy (bound Schottky defect). This picture is obtained postmortem thus after defect recombination. Based on these observations, an interpretation would be that the presence of $\mathrm{Kr}$ atoms favors/stabilizes the aggregation of three vacancies $\left(2 \mathrm{~V}_{\mathrm{O}}+\mathrm{V}_{\mathrm{u}}\right)$ leading to the formation of BSD1. However, recent Positron Annihilation Spectroscopy (PAS) measurements carried out on $\mathrm{UO}_{2}$ samples irradiated with $45 \mathrm{MeV}$ alpha particles showed that Schottky defects are predominant [67]. This would mean that $\mathrm{Kr}$ atoms are preferentially trapped within Schottky defects because the latter are the main stable defects after irradiation/implantation. Unless a higher level model that can account for defect evolution during irradiation, it's not possible to conclude on the mechanism leading to the formation of Kr-BSD1 complex during the implantation process.

The xenon behavior in $\mathrm{UO}_{2}$ for a slightly lower Xe-local concentration ( 0.37 at.\%) has been recently studied by Bès et al. [68] using the same methodology (DFT $+U$ calculations and XAS experiments). Based on their interpretation of the XANES spectra, Bès et al. [68] shows that without annealing after implantation the xenon atoms are mostly in a bound Schottky defect. Thus, for a similar concentration (0.37-0.5 at.\%), the two RGs have the same behavior and they are both stable within a neutral BSD.

The TEM observations performed on either $\mathrm{UO}_{2}$ spent fuels $[7,8]$ or $\mathrm{Kr}$-implanted $\mathrm{UO}_{2}$ [13], Xe-implanted $\mathrm{UO}_{2}$ samples [11,12] show that the same density of nano-objects associated with RG is observed: i.e. $\sim 410^{23}$ objects $\mathrm{m}^{-3}$. This saturation is achieved with local RG concentration greater than 0.1 at.\% which was systematically the case in the present study. Moreover, for a 0.5 at.\% RG concentration, no precipitation of $\mathrm{Kr}$ within nano-cavities was detected in the as-implanted sample. It clearly shows that nanoobjects observed with TEM after RG implantation are nano-voids and contain almost no RG atoms. These nano-voids result from clustering of vacancies due to radiation damages induced by implantation or irradiation processes. These experimental conclusions confirm the results of the classical molecular dynamics simulation presented by Sabathier et al. [15].

This conclusion is in disagreement with the recent work of He et al. [14] where formation of $\mathrm{Kr}$ nano-bubbles in $\mathrm{UO}_{2}$ thin foils was followed by TEM. In this study, $\mathrm{UO}_{2}$ samples were implanted at room temperature with krypton atoms up to a $\mathrm{Kr}$-local concentration of 0.2 at.\% which is close to the implantation conditions B and $C$ used in the present work. The nano-objects density observed was equal to $\sim 4 \cdot 10^{24}$ nano-objects $\mathrm{m}^{-3}$ with $1.1 \mathrm{~nm}$ diameter. Based on the $\mathrm{Kr}$ atoms depth distribution determined by Atom Probe Tomography (APT), the authors assumed that these nano-objects are krypton bubbles. However, as pointed out by He et al. [14], no $\mathrm{Kr}$ ion clusters have been detected during the APT analysis and as a consequence no experimental proof of $\mathrm{Kr}$ atoms presence within the nano-objects is provided. Based on the results shown in the present work and obtained by Sabathier et al. [15], the nano-objects observed at room temperature after implantation by He et al. [14] are most likely empty and $\mathrm{Kr}$ atoms observed by APT are located within bound Schottky defect.

After a thermal treatment at $1273 \mathrm{~K}$ for $12 \mathrm{~h}$, a signal of dense $\mathrm{Kr}$ nano-aggregates is clearly observed even if $26(2) \% \mathrm{of} \mathrm{Kr}$ atoms are still located within defects, most likely BSD1 (for an initial Kr- concentration equals to 0.5 at.\%). The most probable hypothesis is that nano-voids created by radiation damages act as trapping site for diffusing $\mathrm{Kr}$ atoms. For both the krypton and the xenon a RGBSD complex stable in temperature is observed: up to $1273 \mathrm{~K}$ and up to $1673 \mathrm{~K}$ for $\mathrm{Kr}$ and $\mathrm{Xe}$ [68], respectively. It can be assumed that diffusion mechanism determined for Xe is valid for $\mathrm{Kr}$. In recent papers, Andersson et al. $[69,70]$ show that Xe diffusion predominantly occurs via a vacancy-mediated mechanism by binding a uranium vacancy to the RG trap site. The RG migration is dictated by the mobility of U vacancies which has been recently determined by using Kinetic Monte Carlo calculations. At $1273 \mathrm{~K}$ for a stoichiometric $\mathrm{UO}_{2}$, the diffusion coefficient calculated using Goyal et al. [71] for a charged $U$ vacancy is then equal to $1.46 \times 10^{-25} \mathrm{~m}^{2} \mathrm{~s}^{-1}$, which is too low to envisage effective $\mathrm{Kr}$ atom diffusion at $1273 \mathrm{~K}$. As a consequence, considering mechanism based on uranium vacancy migration seems to be in disagreement with our experimental observations.

The krypton diffusion coefficient $\left(\mathrm{D}_{\mathrm{Kr}}\right)$ was determined experimentally by A. Michel [13] using Thermal Desorption Mass Spectrometry on $\mathrm{UO}_{2}$ samples implanted with $\mathrm{Kr}$ ions at a very low concentration (7.5 $\times 10^{-5}$ at.\%). At $1273 \mathrm{~K}$, using A. Michel values, $D_{\mathrm{Kr}}$ is equal to $1.92 \times 10^{-22} \mathrm{~m}^{2} \mathrm{~s}^{-1}$. The krypton diffusion length would be equal to $\sim 2.8 \mathrm{~nm}$ after $12 \mathrm{~h}$-annealing. Such a distance is compatible with a $\mathrm{Kr}$ aggregation via a diffusion mechanism and this relatively short distance could explain that a fraction of $\mathrm{Kr}$ atoms does not precipitate.

\section{Conclusion}

The behavior of krypton in nuclear fuel was studied using XAS experiments at the krypton $\mathrm{K}$ edge in $\mathrm{UO}_{2}$ samples. The latter were implanted with $\mathrm{Kr}$ ions and then annealed between $873 \mathrm{~K}$ and $1673 \mathrm{~K}$ under dry reducing atmosphere $\left(\mathrm{Ar}-5 \% \mathrm{H}_{2}\right)$. The three considered implantation conditions made it possible to determine the influence of both local concentration (0.5 at.\%-8.0 at.\%) and depth $(120 \mathrm{~nm}-1200 \mathrm{~nm})$ on $\mathrm{Kr}$ behavior. The XAS spectra were systematically collected at $15 \mathrm{~K}$ and $300 \mathrm{~K}$ and their interpretation coupled with state-of-the art atomic scale DFT $+U$ calculations lead to the following conclusions:

For a high $\mathrm{Kr}$ local concentration (8.0 at.\%), even after a $12 \mathrm{~h}$ annealing at $873 \mathrm{~K}$, the krypton atoms precipitate as nanometer size aggregates. The krypton density inside these clusters was found to be equal to $4.15(7) \mathrm{g} \mathrm{cm}^{-3}$ and $3.98(5) \mathrm{g} \mathrm{cm}^{-3}$ for asimplanted and $12 \mathrm{~h}$ annealed samples, respectively. By neglecting the effect due to the $\mathrm{UO}_{2}$ matrix, the corresponding krypton pressure values at $300 \mathrm{~K}$ were equal to 2.6(3) GPa and 2.0(2) GPa for asimplanted and annealed $12 \mathrm{~h}$ at $873 \mathrm{~K}$ samples, respectively. As a consequence, these $\mathrm{Kr}$ aggregates are solid at room temperature. After annealing at $1673 \mathrm{~K}$, a bi-modal distribution is observed with dense enough $\mathrm{Kr}$ nano-aggregates to be solid at room temperature and larger cavities only partially filled with $\mathrm{Kr}$ most probably gaseous at $300 \mathrm{~K}$. Comparison with previous separate effects studies on xenon in $\mathrm{UO}_{2}[29,61]$, allows us to conclude that at high concentration $(\sim 8.0$ at.\% RG) the behavior of these two rare gases in $\mathrm{UO}_{2}$ is identical. Furthermore, the properties of the RG dense nanoaggregates observed in both present work and $\mathrm{UO}_{2}$ spent fuels are very similar.

For a 0.5 at\% concentration, without annealing $\mathrm{Kr}$ atoms are incorporated in the $\mathrm{UO}_{2}$ lattice as single atoms mostly inside neutral bound Schottky defects with oxygen vacancies aligned along the (100) direction (BSD1). No influence of either Kr depth location or dpa was observed. The BSD1 is consequently the most predominant defect created by the collision cascades occurring through the implantation process. Furthermore, our experimental results clearly shows that nano-objects observed after a RG 
implantation are nanovoids resulting from clustering of vacancies due to radiation damaged induced by implantation or irradiation processes. The presence of dense $\mathrm{Kr}$ nano-clusters, most probably solid at room temperature, is detected after annealing at $1273 \mathrm{~K}$ for $12 \mathrm{~h}$. However, $26 \pm 2 \%$ of the $\mathrm{Kr}$ atoms still remain within BSD1. The Kr-BSD1 complex is therefore stable at least up to this temperature. Therefore, the (in-)solubility of heavy $\mathrm{RG}$ in $\mathrm{UO}_{2}$ has to be re-evaluated especially during irradiation in nuclear reactor where a constant creation of defects due to fission occurs.

After a 4 h-annealing at $1673 \mathrm{~K}$, a bi-modal distribution of $\mathrm{Kr}$ aggregates with the same properties (size, density) as observed for the concentrated sample ( 8.0 at.\% $\mathrm{Kr})$ is detected. The difference in the local $\mathrm{Kr}$ concentration modifies only its repartition between the two types of cavities, the large cavities only partially filled with $\mathrm{Kr}$ are barely observed in the 0.5 at.\% Kr sample. So, even at temperature up to $1673 \mathrm{~K}$, dense nanometer-sized RG aggregates in $\mathrm{UO}_{2}$ is observed to be stable. Furthermore, our work shows that rare gas can be used as a probe to study the defect creation and their stability in $\mathrm{UO}_{2}$.

\section{Acknowledgments}

The authors acknowledge $C$. Tanguy (CEA Cadarache) for sample preparation. The authors are also grateful to Romain Vauchy, Jean Noirot, Rene Bès and Michal Strach (CEA Cadarache) whose careful reading of this paper led to a number of improvements. We acknowledge the European Synchrotron Radiation Facility and the French CRG committees for provision of synchrotron radiation beamtime. Authors are grateful to CEA and EDF for funding these activities within the frame of the PRECCI project.

\section{References}

[1] D.D. Baron, L. Hallstadius, in: Rudy J.M. Konings (Ed.), Compr. Nucl. Mater. Elsevier, Oxford, 2012, pp. 481-514.

[2] D.R. Olander, Nuclear Reactor Fuel Elements; National Technical Information Services, Document No. 26711, 1976.

[3] J. Noirot, L. Desgranges, J. Lamontagne, J. Nucl. Mater. 372 (2008) 318-339.

[4] P. Carbol, D.H. Wegen, T. Wiss, P. Fors, in: R.J.M. Konings (Ed.), Compr. Nucl. Mater., Elsevier, Oxford, 2012, pp. 389-420.

[5] C. Ferry, J.-P. Piron, A. Ambard, J. Nucl. Mater. 407 (2010) 100-109.

[6] P. Garcia, G. Martin, C. Sabathier, G. Carlot, A. Michel, P. Martin, B. Dorado, M. Freyss, M. Bertolus, R. Skorek, J. Noirot, L. Noirot, O. Kaitasov, S. Maillard, Nucl. Instrum. Methods Phys. Res. Sect. B Beam Interact. Mater. Atoms 277 (2012) 98-108.

[7] K. Nogita, K. Une, J. Nucl. Mater. 250 (1997) 244-249.

[8] K. Nogita, K. Une, Nucl. Instrum. Methods Phys. Res. Sect. B Beam Interact. Mater. Atoms 141 (1998) 481-486.

[9] L.E. Thomas, in: S.E. Donnelly, J.H. Evans (Eds.), Fundam. Asp. Inert Gases Solids, Plenum Publishing Corporation, New York, London, 1991, pp. 431-442.

[10] L.E. Thomas, C.E. Beyer, L.A. Chariot, J. Nucl. Mater. 188 (1992) 80-89.

[11] A. Michel, C. Sabathier, G. Carlot, O. Kaïtasov, S. Bouffard, P. Garcia, C. Valot, Nucl. Instrum. Methods Phys. Res. Sect. B 272 (2012) 218-221.

[12] C. Sabathier, L. Vincent, P. Garcia, F. Garrido, G. Carlot, L. Thome, P. Martin, C. Valot, Nucl. Instrum. Methods Phys. Res. Sect. B Beam Interact. Mater. Atoms 266 (2008) 3027-3032.

[13] A. Michel, Etude Du Comportement Des Gaz de Fission Dans Le Dioxyde D'uranium: Mécanismes de Diffusion, Nucléation et Grossissement de Bulles (Phd thesis), Université de Caen, France, 2011.

[14] L.F. He, B. Valderrama, A.-R. Hassan, J. Yu, M. Gupta, J. Pakarinen, H.B. Henderson, J. Gan, M.A. Kirk, A.T. Nelson, M.V. Manuel, A. El-Azab, T.R. Allen, J. Nucl. Mater. 456 (2015) 125-132.

[15] C. Sabathier, G. Martin, A. Michel, G. Carlot, S. Maillard, C. Bachelet, F. Fortuna, O. Kaitasov, E. Oliviero, P. Garcia, Nucl. Instrum. Methods Phys. Res. Sect. B Beam Interact. Mater. Atoms 326 (2014) 247-250.

[16] A. Polian, J.P. Itie, E. Dartyge, A. Fontaine, G. Tourillon, Phys. Rev. B 39 (1989) 3369.

[17] A. Di Cicco, A. Filipponi, J.P. Itié, A. Polian, Phys. Rev. B 54 (1996) 9086.

[18] G. Faraci, A.R. Pennisi, J.-L. Hazemann, Phys. Rev. B 56 (1997) 12553.

[19] Z. Tan, J.I. Budnick, D.M. Pease, F. Namavar, Phys. Rev. B 43 (1991) 1987.

[20] R. Wulf, G. Calas, A. Ramos, H. Büttner, K. Roselied, M. Rosenhauer, Am. Mineral. 84 (1999) 1461.

[21] R.G. Lacerda, L.R. Tessler, M.C. dos Santos, P. Hammer, F. Alvarez, F.C. Marques,
J. Non-Cryst. Solids 299-302 (2) (2002) 805-809.

[22] S. Ito, A. Takeda, T. Miyazaki, Y. Yokoyama, M. Saunders, R.J. Cross, H. Takagi, P. Berthet, N. Dragoe, J. Phys. Chem. B 108 (2004) 3191-3195.

[23] C. Degueldre, C. Mieszczynski, C. Borca, D. Grolimund, M. Martin, J. Bertsch, Nucl. Instrum. Methods Phys. Res. Sect. B Beam Interact. Mater. Atoms 336 (2014) 116-122.

[24] R.W. Grimes, C.R.A. Catlow, Philos. Trans. R. Soc. Phys. Eng. Sci. 335 (1991) 609-634.

[25] T. Petit, M. Freyss, P. Garcia, P. Martin, M. Ripert, J.-P. Crocombette, F. Jollet, J. Nucl. Mater. 320 (2003) 133-137.

[26] A.E. Thompson, C. Wolverton, Phys. Rev. B 84 (2011) 134111.

[27] X. Tian, T. Gao, G. Jiang, D. He, H. Xiao, Comput. Mater. Sci. 54 (2012) 188-194.

[28] O. Bunău, Y. Joly, J. Phys. Condens. Matter 21 (2009) 345501.

[29] P. Martin, P. Garcia, G. Carlot, C. Sabathier, C. Valot, V. Nassif, O. Proux, J.L. Hazemann, Nucl. Instrum. Methods Phys. Res. Sect. B Beam Interact. Mater. Atoms 266 (2008) 2887-2891.

[30] J.F. Ziegler, J.P. Biersack, U. Littmark, The Stopping and Range of Ions in Solids, Pergamon Press, New York, 1985.

[31] O. Proux, X. Biquard, E. Lahera, J.-J. Menthonnex, A. Prat, O. Ulrich, Y. Soldo, P. Trévisson, G. Kapoujyan, G. Perroux, P. Taunier, D. Grand, P. Jeantet, M. Deleglise, J.-P. Roux, J.-L. Hazemann, Phys. Scr 2005 (2005) 970.

[32] O. Proux, V. Nassif, A. Prat, O. Ulrich, E. Lahera, X. Biquard, J.-J. Menthonnex, J.L. Hazemann, J. Synchrotron Radiat. 13 (2005) 59-68.

[33] J.A. Bearden, A.F. Burr, Rev. Mod. Phys. 39 (1967) 125-142.

[34] C. Gauthier, V.A. Solé, R. Signorato, J. Goulon, E. Moguiline, J. Synchrotron Radiat. 6 (1999) 164-166.

[35] P. Glatzel, T.-C. Weng, K. Kvashnina, J. Swarbrick, M. Sikora, E. Gallo, N. Smolentsev, R.A. Mori, J. Electron Spectrosc. Relat. Phenom. 188 (2013) $17-25$.

[36] I. Llorens, E. Lahera, W. Delnet, O. Proux, A. Braillard, J.-L. Hazemann, A. Prat, D. Testemale, Q. Dermigny, F. Gelebart, M. Morand, A. Shukla, N. Bardou, O. Ulrich, S. Arnaud, J.-F. Berar, N. Boudet, B. Caillot, P. Chaurand, J. Rose, E. Doelsch, P. Martin, P.L. Solari, Rev. Sci. Instrum. 83 (2012) 063104-063104-9.

[37] B. Ravel, M. Newville, J. Synchrotron Radiat. 12 (2005) 537-541.

[38] Q. Wang, C. Li, X. Niu, R. Shen, K. Lu, S. Wei, Z. Wu, T. Liu, Y. Xie, T. Hu, Phys, Rev. B Condens. Matter Mater. Phys. 72 (2005) 092202-092204.

[39] A.L. Ankudinov, B. Ravel, J.J. Rehr, S.D. Conradson, Phys. Rev. B 58 (1998) 7565.

[40] J.-P. Rueff, A. Shukla, J. Electron Spectrosc. Relat. Phenom. 188 (2013) 10-16.

[41] M.O. Krause, J.H. Oliver, J. Phys, Chem. Ref. Data 8 (1979) 329-338.

[42] G. Kresse, D. Joubert, Phys. Rev. B 59 (1999) 1758-1775.

[43] P.E. Blöchl, Phys. Rev. B 50 (1994) 17953-17979.

[44] G. Kresse, J. Furthmüller, Phys. Rev. B 54 (1996) 11169-11186.

[45] G. Kresse, J. Hafner, Phys. Rev. B 47 (1993) 558-561.

[46] G. Kresse, J. Furthmüller, Comput. Mater. Sci. 6 (1996) 15-50.

[47] J.P. Perdew, K. Burke, M. Ernzerhof, Phys. Rev. Lett. 77 (1996) 3865-3868.

[48] A.I. Liechtenstein, V.I. Anisimov, J. Zaanen, Phys. Rev. B 52 (1995) R5467-R5470.

[49] S.L. Dudarev, D.N. Manh, A.P. Sutton, Philos. Mag. Part B 75 (1997) 613-628.

[50] A. Kotani, T. Yamazaki, Prog. Theor. Phys. Suppl. 108 (1992) 117-131.

[51] B. Dorado, B. Amadon, M. Freyss, M. Bertolus, Phys. Rev. B 79 (2009) 235125.

[52] K. Ikushima, S. Tsutsui, Y. Haga, H. Yasuoka, R.E. Walstedt, N.M. Masaki, A. Nakamura, S. Nasu, Y. Ōnuki, Phys. Rev. B 63 (2001) 104404.

[53] R. Laskowski, G.K.H. Madsen, P. Blaha, K. Schwarz, Phys. Rev. B 69 (2004) 140408.

[54] Hendrik J. Monkhorst, J.D. Pack, Phys. Rev. B 13 (1976) 5188-5192.

[55] M. Idiri, T. Le Bihan, S. Heathman, J. Rebizant, Phys. Rev. B 70 (2004) 014113.

[56] M. Newville, J. Synchrotron Radiat. 8 (2001) 322-324.

[57] T. Yokoyama, T. Ohta, H. Sato, Phys. Rev. B 55 (1997) 11320-11329.

[58] E. Vathonne, J. Wiktor, M. Freyss, G. Jomard, M. Bertolus, J. Phys. Condens. Matter 26 (2014) 325501.

[59] A.P. Jephcoat, Nature 393 (1998) 355-358.

[60] S.T. Murphy, A. Chartier, L. Van Brutzel, J.-P. Crocombette, Phys. Rev. B 85 (2012) 144102.

[61] P. Garcia, P. Martin, G. Carlot, E. Castelier, M. Ripert, C. Sabathier, C. Valot, F. D'Acapito, J.-L. Hazemann, O. Proux, V. Nassif, J. Nucl. Mater. 352 (2006) 136-143.

[62] S. Kashibe, K. Une, K. Nogita, J. Nucl. Mater. 206 (1993) 22-34.

[63] G. Martin, P. Garcia, C. Sabathier, F. Devynck, M. Krack, S. Maillard, Nucl. Instrum. Methods Phys. Res. Sect. B Beam Interact. Mater. Atoms 327 (2014) $108-112$.

[64] G. Martin, P. Garcia, L. Van Brutzel, B. Dorado, S. Maillard, Nucl. Instrum. Methods Phys. Res. Sect. B Beam Interact. Mater. Atoms 269 (2011) 1727-1730.

[65] C. Sabathier, G. Martin, A. Michel, G. Carlot, S. Maillard, C. Bachelet, F. Fortuna, O. Kaitasov, E. Oliviero, P. Garcia, Nucl. Instrum. Methods Phys. Res. Sect. B Beam Interact. Mater. Atoms 326 (2014) 247-250.

[66] L.-F. He, M. Gupta, C.A. Yablinsky, J. Gan, M.A. Kirk, X.-M. Bai, J. Pakarinen, T.R. Allen, J. Nucl. Mater. 443 (2013) 71-77.

[67] J. Wiktor, M.-F. Barthe, G. Jomard, M. Torrent, M. Freyss, M. Bertolus, Phys. Rev. B 90 (2014) 184101

[68] R. Bès, P. Martin, E. Vathonne, R. Delorme, C. Sabathier, M. Freyss, M. Bertolus, 
P. Glatzel, Appl. Phys. Lett. 106 (2015) 114102.

[69] D.A. Andersson, B.P. Uberuaga, P.V. Nerikar, C. Unal, C.R. Stanek, Phys. Rev. B 84 (2011) 054105.

[70] D.A. Andersson, P. Garcia, X.-Y. Liu, G. Pastore, M. Tonks, P. Millett, B. Dorado,
D.R. Gaston, D. Andrs, R.L. Williamson, R.C. Martineau, B.P. Uberuaga, C.R. Stanek, J. Nucl. Mater. 451 (2014) 225-242.

[71] A. Goyal, S.R. Phillpot, G. Subramanian, D.A. Andersson, C.R. Stanek B.P. Uberuaga, Phys. Rev. B 91 (2015) 094103. 